\title{
On Transport Service Selection in Intermodal Rail/Road Distribution Networks
}

Christian Bierwirth, School for Economics and Business, Martin-Luther-University Halle-Wittenberg, Germany, E-mail: christian.bierwirth@wiwi.uni-halle.de

Thomas Kirschstein, School for Economics and Business, Martin-Luther-University Halle-Wittenberg, Germany, E-Mail: thomas.kirschstein@wiwi.uni-halle.de

Frank Meisel, School for Economics and Business, Martin-Luther-University Halle-Wittenberg, Germany, E-Mail: frank.meisel@wiwi.uni-halle.de

\begin{abstract}
Intermodal rail/road freight transport constitutes an alternative to long-haul road transport for the distribution of large volumes of goods. The paper introduces the intermodal transportation problem for the tactical planning of mode and service selection. In rail mode, shippers either book train capacity on a per-unit basis or charter block trains completely. Road mode is used for short-distance haulage to intermodal terminals and for direct shipments to customers. We analyze the competition of road and intermodal transportation with regard to freight consolidation and service cost on a model basis. The approach is applied to a distribution system of an industrial company serving customers in eastern Europe. The case study investigates the impact of transport cost and consolidation on the optimal modal split.
\end{abstract}

JEL-classification: R41, M11, L92

Keywords: intermodal transportation problem, service selection, transport cost rates, sustainable transport chain

Manuscript received April 23, 2012, accepted by Karl Inderfurth (Operations and Information Systems) July 25, 2012.

\section{Introduction}

Intermodal freight transport reflects the combination of two or more modes of transport (e.g., road, rail, water) within a single transport chain. It is generally assumed that the moved goods are containerized and, thus, allow a standardized handling during the transfer between any two modes involved in the transport. Intermodal freight transport is receiving increasing attention in the European transport economy as it is considered a way to increase traffic safety, and to reduce road congestion and air pollution at the same time (European Communities 2002).

In this paper we concentrate on intermodal rail/road transport from the viewpoint of a large shipper organization. Today, many shippers consider intermodal transportation as an alternative for delivering goods to customers instead of long-haul road transports from the shipper's door to the customer's door. However, several prerequisites must hold in order to make the intermodal transport of goods profitable.

1. The cost rate per transport unit and kilometer must be significantly smaller in rail transportation than in road transportation. Otherwise, the intermodal transport cost would exceed the road transport cost because the traveling distance of an intermodal chain is always longer than the direct distance from door to door.

2. The hauling distance between the shipper's door and the customer's door must be above a certain break-even distance. This is because the cost incurred by an intermodal transport includes additional fees which are charged by intermodal terminal operators for transferring a transport unit from road to rail or from rail to 
road. The cost advantage of rail transport can only compensate the additional fees beyond a certain distance covered by rail carriage.

3. The transport is not time critical as it is known that intermodal transport usually takes considerably more time compared to direct road transport.

Shippers must have a model for intermodal transport planning which is different from models used for planning the long-haul road transports. Such a model aims at deciding on the transport facilities to use and on the capacity that needs to be provided by carriers on each transport mode in order to realize a cost-effective flow of cargo. The contribution of this paper is to provide such a model for the tactical transportation planning. It incorporates the selection of modes of transport, transport services, and the consolidation of cargo flows. Scalable cost functions for road and rail transport are included in the model in order to consider realistic cost rates for the transshipment and movement of goods. This way, economies of scale and consolidation effects are captured in the model.

It is shown by a real-world case study how optimal transport decisions can be made in a distribution network with competing rail and road transport services. For this purpose, we consider a company which produces a certain good in a couple of sites located within one region. The demand region where the customers reside is far from the supply region. There are three distinct services available for the transport of goods. In the first service, called door-to-door (D2D), a transport unit is moved directly from a production site to a customer's location by means of a road transport. In both other transport services, the goods are first moved by truck to an intermodal terminal located in the origin region, then moved by train to an intermodal terminal of the destination region, and finally moved by truck from the destination terminal to the customer. The rail transport, which takes most of the transport distance, can either appear in less-than-train load (LTL) mode where a company pays a charge for each unit of load, or in full-train-load (FTL) mode where the company charters a block train as a whole.

The paper is organized as follows. In section 2, we briefly review the relevant literature and show that our approach takes a new perspective not yet investigated. In section 3, a tactical transportation planning model is presented which can be used by shippers to decide on serving customers by road, intermodal rail/road transportation, or a mixture thereof. This includes also identifying realistic cost functions and freight consolidation effects, which are incorporated in a mathematical optimization model. Section 4 illustrates the model by a small problem instance to shed light on the impact of cost and the structure of optimal decisions. Section 5 presents a case study for a company that serves customers in eastern Europe from production sites in western Europe. The paper is concluded in section 6.

\section{Literature}

The growing interest in sustainable (or green) logistics has also given rise to the rapid progress of scientific literature on intermodal transportation. A framework classifying the diverse contributions in this field was proposed by Macharis and Bontekoning (2004) and Caris, Macharis, and Janssens (2008). In these survey papers the authors employed a classification which contains 12 categories combining (i) the type of operator that faces an operations problem in the intermodal transportation chain and (ii) the time horizon of the problem. It is distinguished between

- drayage operators, who move goods by truck between intermodal terminals and the shippers and receivers,

- terminal operators, who transship goods from road to rail and from rail to road,

- network operators, who carry goods within the railway network, and,

- intermodal operators, who represent the users of the intermodal infrastructure.

Intermodal operators are either shippers or receivers themselves, or freight forwarders who organize the carriage of goods on behalf of the shippers or the receivers. The length of the time horizon of a problem assigns it to the strategic, tactical or operational level. Long-term decisions in intermodal transportation are for instance the location and layout planning of intermodal terminals, and the railway network design. Medium-term or tactical problems deal with the capacity planning of 
equipment and the development of consolidation and pricing strategies. Short-term problems address the routing and scheduling of trucks, the load planning of trains, and the redistribution of containers and railcars.

Basically, the mentioned problems are faced either by drayage, terminal or network operators, while the intermodal operator is only concerned with the operational problem of selecting transport routes and services as offered by other operators. Only a few papers addressed the category of operational problems faced by an intermodal operator.

Min (1991) considered an international supply chain connecting suppliers in Japan with a receiver in the US. The shipper can decide on using various intermodal chains, combining road, rail, air and deep-sea transportation, where both, cost and time, are of concern. A goal programming approach is proposed which allows model solutions and their response to be analyzed regarding changes of freight rates, charges for loading and storage, and transit times. In order to achieve minimum cost routes and schedules in general origin-destination networks, Barnhart and Ratliff (1993), Boardman, Malstrom, Butler, and Cole (1997), and Ziliaskopoulos and Wardell (2000) as well as Chang (2008) and Verma, Verter, and Zufferey (2012) adapted concepts of shortest paths algorithms. This stream of research aims at providing operational assistance to intermodal operators to identify the optimal path for an individual shipment in a network with various transport modes available. Verma, Verter, and Zufferey (2012) proposed an intermodal routing problem in a railroad network for containerized hazardous materials. Here, the objective is not only to minimize transportation cost but also to reduce the expected risk inherited by a specific mode of transportation. A more holistic view was taken by Erera, Morales, and Savelsbergh (2005). These authors considered an intermodal operator managing a homogeneous fleet of tank containers. The containers are moved between shippers and customers in a global transport network. An integrated model is proposed for routing containers and repositioning empty containers, which is solved as a multi-commodity network flow problem.

In contrast to the above research, our paper focuses on the question of how intermodal transportation can be put in competition with road transportation. Thereby we concentrate particularly on large shipper organizations residing at multiple locations and producing large volumes of output. If a large shipper acts as an intermodal operator, also tactical transport decisions come into the fore. Those decisions comprise, for example, the allocation of a production site to an intermodal terminal and the freight consolidation of shipments in the railway network. Papers dealing with strategic and tactical issues of intermodal operators are as yet unknown. In the framework of Macharis and Bontekoning (2004), tactical operation problems are only assigned to the other types of operators. This is because a perspective of small and mediumsized shippers is taken, who delegate the tactical decisions to drayage and network operators. The relevant literature of these categories is briefly reviewed below.

The assignment problem of shipper and customer locations to a terminal's service area is referred to as the intermodal ramp selection or intermodal terminal location problem (Taylor, Broadstreet, Meinert, and Usher 2002). This problem was modeled as a binary linear program by Arnold, Peeters, and Thomas (2004) and solved by a heuristic called Intermodal Terminal Location Simulation System (ITLSS) for a real-world case observed in Spain. In a recent paper, Sörensen, Vanovermeire, and Busschaert (2012) addressed the same problem by two meta-heuristics, namely a Greedy Randomized Adaptive Search Procedure (GRASP) and an Attribute-Based Hill Climber (ABHC). For a set of randomly generated test instances, both methods are able to discover solutions nearby the optimal solution. Ishfaq and Sox (2010) provided a model for intermodal terminal location that also allows direct shipments by road transports. Economies of scale are reflected by non-linear transport costs. They propose a tabu search procedure which is able to find near-optimal solutions for networks with up to 20 terminals. This branch of literature is still growing with focus, e.g., on the incorporation of different service types, see Ishfaq (2012), or on different transport units, see Meng and Wang (2011). However, all approaches assume a set of predefined transport orders with given origins and destinations. In contrast, in this paper we are given production quantities and customer demands where the flow and consolidation of goods is the subject of the optimization.

Closely related with the intermodal terminal location problem is the freight consolidation 
problem faced at an intermodal terminal. Obviously, the more shipment volume is allocated to a certain terminal, the better a network operator can consolidate the inbound and outbound transport operations. At the tactical level, network operators have to decide about the frequency of a service, the assignment of equipment and capacity to services, the lengths of trains, and the like (Nozick and Morlok 1997). These decisions basically influence the cost contribution of the rail carriage in the intermodal transport and thus have a strong impact on competitiveness. Spasovic and Morlok (1993) estimated that rail contributes between $60 \%$ to $75 \%$ of the total origin-destination cost in the intermodal transportation. Kim and Van Wee (2011) provided a thorough survey on the cost of intermodal transports. By means of simulation, the relative importance of the various costs of an intermodal transport is studied. It is found that the costs of long-haul road and rail transports have the highest impact on the cost-effectiveness of intermodal transports. In the absence of realistic cost information, Sörensen, Vanovermeire, and Busschaert (2012) determined transport cost by the Euclidean distance between origin and destination and incorporate a rail discount through dividing the covered rail distance by two. Estimate functions for true cost rates in road and rail traffic were provided by Janic $(2007,2008)$.

In this paper, we take the position that the mentioned tactical problems are in the responsibility of the shipper. We investigate the selection problem of terminals in the origin and in the destination area together with the freight consolidation problem for the rail transport. The latter problem also includes choosing LTL, FTL, and D2D transport services. The cost effects of these decisions are included in a function used for estimating the total cost of all considered transport services.

\section{The Intermodal Transportation Problem}

In this section, we formally describe the considered planning problem, identify realistic cost functions and freight consolidation effects, and provide a mathematical optimization model. The notation used for modeling the problem is summarized in Tab. 1 .

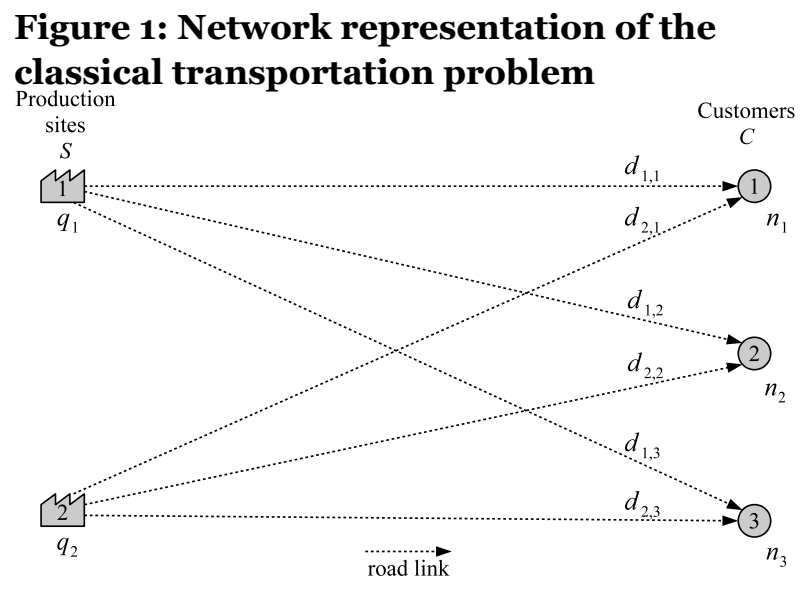

\subsection{Notation and assumptions}

In the intermodal transportation problem (ITP), a set of customers $\mathcal{C}$ and a set of production sites $\mathcal{S}$ are given. The production sites produce a certain product that is demanded by customers. The demand of customer $c \in \mathcal{C}$, measured in transport units (TUs), is denoted by $n_{c}$. The production output of site $s \in \mathcal{S}$, measured in TUs, is denoted by $q_{s}$. It is assumed that the company's production plan is such that total output equals total demand. Generally, shipments can be sent on a per-TU basis from production sites to customer locations by a D2D road transport service. The corresponding truck travel distance between nodes $s \in \mathcal{S}$ and $c \in \mathcal{C}$ in the network is denoted by $d_{s c}$ and the corresponding cost rate per TU and kilometer $(\mathrm{km})$ is denoted by $c^{\mathrm{D} 2 \mathrm{D}}$. Suppose the shipper aims at minimizing the total cost of transportation using exclusively D2D services, then the resulting problem resembles the classical transportation problem, Dantzig and Thapa (1997). This situation is illustrated in Fig. 1 for a network with two production sites and three customers.

In the ITP, shippers are also given the opportunity to ship goods by rail. In general, next to production sites and customer locations, so-called intermodal terminals are available in the logistics network, enabling the transfer of TUs from road to rail or vice versa. In the following, it is assumed that the shipper has already preselected a set of terminals to be potentially used for intermodal transportation, leading to a network that contains two subsets $\mathcal{O}$ and $\mathcal{D}$ of intermodal terminals. Terminals $o \in \mathcal{O}$ are located in the origin area where the production sites reside. They receive goods from the production sites and distribute them to 


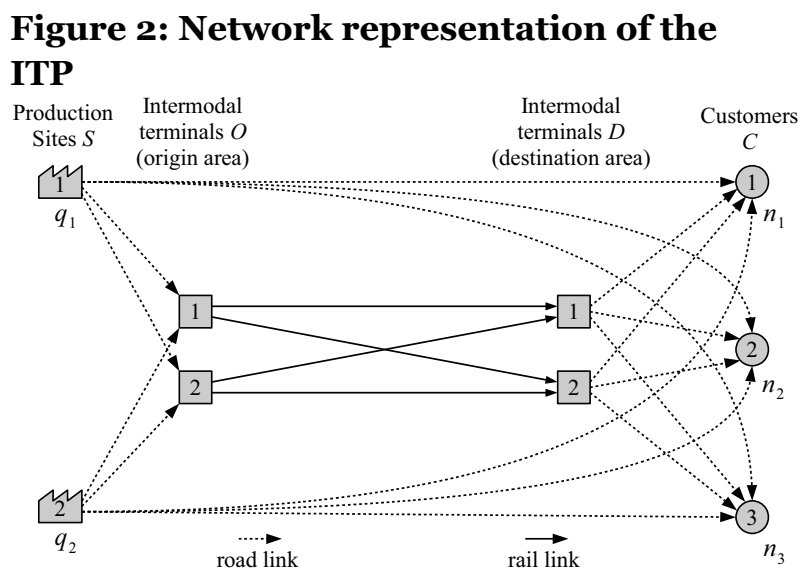

terminals $d \in \mathcal{D}$ in the destination area, where the customers reside. Fig. 2 shows a simple intermodal network consisting of two origin terminals and two destination terminals. In order to perform an intermodal rail/road transport, a pre-carriage for shipping goods from production sites to terminals $o \in \mathcal{O}$ and a post-carriage for shipping goods from terminals $d \in \mathcal{D}$ to customers is done by road transportation while transportation between terminals $o$ and $d$ is bridged by a long-haul rail transportation. In this logistics network, the set of nodes is given by $\mathcal{N}=\mathcal{S} \cup \mathcal{O} \cup \mathcal{D} \cup \mathcal{C}$. The set of road connections is defined by $\mathcal{A}=\mathcal{S} \times \mathcal{C} \cup \mathcal{S} \times \mathcal{O} \cup \mathcal{D} \times \mathcal{C}$ and the set of rail connections is represented by $\mathcal{B}=\mathcal{O} \times \mathcal{D}$.

Typically, rail operators provide two different types of services to shippers. In FTL service, the shipping company charters a complete block train, which provides a capacity of $\mathrm{cap}^{\mathrm{FTL}} \mathrm{TUs}$. For this service, the shipper has to meet a cost rate of $\tilde{c}^{\mathrm{FTL}}$, which is measured in $€$ per kilometer traveled by the block train. In LTL service, train capacity is booked by shippers on a per-TU basis. Here, the shipper has to meet a cost $c^{\mathrm{LTL}}$ per TU-km. In practice, the cost for FTL transportation allows a saving over LTL transportation cost provided a sufficiently large number of TUs can be consolidated within one chartered block train.

Given the output volume of the production sites, the ITP is to decide on the usage of D2D, FTL, and LTL services such that customer demand is fulfilled at minimum total transportation cost. In particular, this problem includes deciding on the number of block trains to be chartered, on the number of TUs send by LTL service, and, finally, on
Table 1: Notation

\begin{tabular}{|c|c|}
\hline \multicolumn{2}{|c|}{ Network: } \\
\hline $\mathcal{C}$ & set of customers \\
\hline $\mathcal{S}$ & set of production sites \\
\hline $\mathcal{O}$ & set of terminals in the origin area \\
\hline $\mathcal{D}$ & set of terminals in the destination area \\
\hline $\mathcal{N}$ & set of nodes, $\mathcal{N}=\mathcal{S} \cup \mathcal{O} \cup \mathcal{D} \cup \mathcal{C}$ \\
\hline $\mathcal{A}$ & $\begin{array}{l}\text { set of road transport arcs, } \\
\mathcal{A}=\mathcal{S} \times \mathcal{C} \cup \mathcal{S} \times \mathcal{O} \cup \mathcal{D} \times \mathcal{C}\end{array}$ \\
\hline $\mathcal{B}$ & set of rail transport arcs, $\mathcal{B}=\mathcal{O} \times \mathcal{D}$ \\
\hline$d_{i j}$ & distance between nodes $i \in \mathcal{N}$ and $j \in \mathcal{N}$ \\
\hline \multicolumn{2}{|c|}{ Services: } \\
\hline D2D & direct door-to-door road transport \\
\hline FTL & full-train-load rail service \\
\hline LTL & less-than-train-load rail service \\
\hline \multicolumn{2}{|c|}{ Quantities and capacities: } \\
\hline$q_{s}$ & quantity provided at site $s \in \mathcal{S}$ \\
\hline & demand of customer $c \in \mathcal{C}$ \\
\hline \multirow{2}{*}{\multicolumn{2}{|c|}{$\begin{array}{l}\operatorname{cap}^{\mathrm{FTL}} \text { load capacity of a block train (in TU) } \\
\overline{c a p}^{\mathrm{FTL}} \text { break-even capacity (in TU) }\end{array}$}} \\
\hline & \\
\hline \multicolumn{2}{|c|}{ Cost rates: } \\
\hline$c^{\mathrm{D} 2 \mathrm{D}}$ & D2D cost rate per TU-km \\
\hline$c^{\text {pre }}$ & pre-carriage cost rate per TU-km \\
\hline$c^{\text {post }}$ & post-carriage cost rate per TU-km \\
\hline$\tilde{c}^{\mathrm{FTL}}$ & FTL cost rate per train-km \\
\hline$c^{\mathrm{FTL}}$ & FTL cost rate per TU-km, $c^{\mathrm{FTL}}=\frac{\tilde{c}^{\mathrm{FTL}}}{c a p^{\mathrm{FTL}}}$ \\
\hline$c^{\mathrm{LTL}}$ & LTL cost rate per TU-km with $c^{\mathrm{LTL}} \geq c^{\mathrm{FTL}}$ \\
\hline \multicolumn{2}{|c|}{ Decision variables: } \\
\hline$x_{i j}$ & flow of TUs on $\operatorname{arc}(i, j) \in \mathcal{A} \cup \mathcal{B}$ \\
\hline$x_{o d}^{\mathrm{LTL}}$ & LTL flow of TUs on rail $\operatorname{arc}(o, d) \in \mathcal{B}$ \\
\hline$y_{o d}$ & $\begin{array}{l}\text { number of chartered block trains on rail } \\
\operatorname{arc}(o, d) \in \mathcal{B}\end{array}$ \\
\hline$z_{\text {od }}$ & $\begin{array}{l}\text { binary, } 1 \text { iff a block train is chartered for } \\
\text { a shipment volume above } \overline{c a p}^{\mathrm{FTL}} \text { and } \\
\text { below cap }{ }^{\mathrm{FTL}} \text { on rail arc }(o, d) \in \mathcal{B}\end{array}$ \\
\hline
\end{tabular}

road shipments for pre-carriage, post-carriage, and D2D services. To summarize, the ITP considered in this paper is characterized as follows:

- All input data is known and deterministic. Volume of goods is measured in transport units (TUs), distance is measured in kilometer $(\mathrm{km})$, and cost is measured in Euro $(€)$.

- The truck load capacity is given by one TU and the train load capacity is given by a fixed multi- 
ple of TUs. This enables a straight transformation of truck shipments into train loads when consolidating cargo in an intermodal terminal.

- Production output, transport flow, and demand of goods consider a single type of commodity. The total output of production sites equals the total customer demand.

- The production sites are clustered in one geographical area (called the origin area). The customer locations constitute a second cluster (the destination area). Rail links connect the intermodal terminals in both areas. Such a network structure is observed, for instance, when an industrial region serves a foreign market.

- In the ITP, schedules for truck and train travels as well as handling times at the intermodal terminals are out of scope.

\subsection{Modeling cost and freight consolidation effects}

In order to generate reliable solutions from the ITP, realistic cost rates for road and rail transportation as well as freight consolidation effects must be considered in the planning model. Typically, in road transportation, vehicle cost per traveled kilometer obeys economies of scale, i.e. cost decrease with the length of the hauling distance. The total traveling cost of a vehicle contains fixed cost, including, e.g., loading and stop cost, and variable cost depending on the distance traveled. Since fixed costs are shared among the traveled distance units, a decrease in the total cost per traveled kilometer is observed. Furthermore, short-distance trips are often performed at lower average speed compared to long-distance trips. Hence, costs incurred on a time basis, like salary of truck drivers, have a stronger impact on the cost per kilometer in shortdistance transport.

Several studies provide models for capturing these effects within cost functions for road transport operations, e.g., Forkenbrock (2001), Smart and Game (2006), Janic (2007, 2008). The model of Janic (2007) describes these effects for road transportation within the European Union. It quantifies the average cost per vehicle-kilometer $c^{\text {road }}$ by an inverse exponential function of the haulage distance $d$ as

(1) $c^{\mathrm{road}}(d)=€ 5.46 \cdot d^{-0.278}$

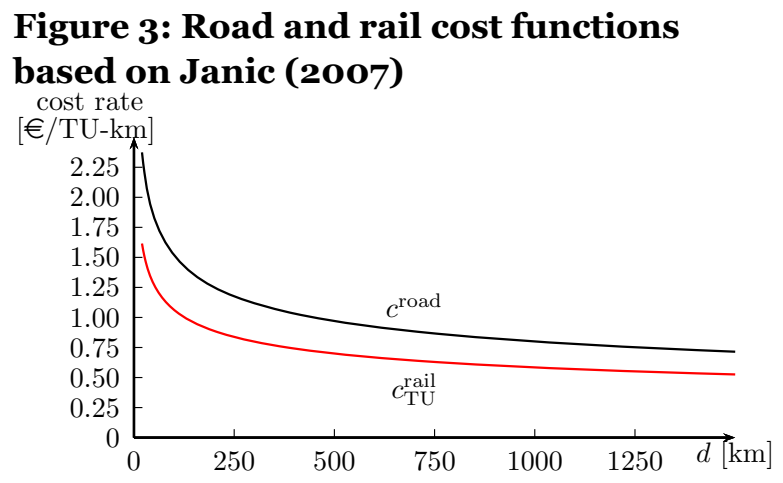

per vehicle-km. Since we define the load capacity of a truck by one TU, the vehicle cost function (1) can be used to determine the cost per TU-km at the same time. The function $c^{\text {road }}(d)$ is depicted in the upper curve of Fig. 3. To simplify the formulation of the ITP, we derive individual cost rates from this function for the pre-carriage, the post-carriage, and for the D2D service. Cost rate $c^{\text {pre }}$ is calculated from the average distance between all production sites and all terminals in the origin area. Cost rate $c^{\text {post }}$ is obtained in the same way from the average distance between terminals in the destination area and the customer locations. This simplification is justified by the fact that freight carriers usually charge the same cost rate for services that take place within a same region. Finally, the cost rate $c^{\mathrm{D} 2 \mathrm{D}}$ is obtained from the average door-todoor distance between the production sites and customer locations.

Decreasing cost per traveled kilometer is also observed in rail transportation. Janic (2007) specified average train travel cost per kilometer as a function of train gross weight $w$ and the hauling distance $d$. It is calculated by

(2) $c^{\text {rail }}(d, w)=€ 0.58 \cdot w^{0.74} \cdot d^{-0.26}$

per train-km. The author also reported the average gross weight of $w=1560$ tons for freight trains in Europe. Corresponding information for Australia and the US is provided by Forkenbrock (2001) and Smart and Game (2006).

In order to derive the cost per TU-km for rail transportation, the load capacity of a block train $c a p^{\mathrm{FTL}}$ must be taken into consideration. Because of technical limits regarding the maximal gross weight and the maximal overall length of trains, $c a p^{\mathrm{FTL}}=38$ TUs is observed in western Europe 


\section{Figure 4: Cost function for consolidated rail transports}

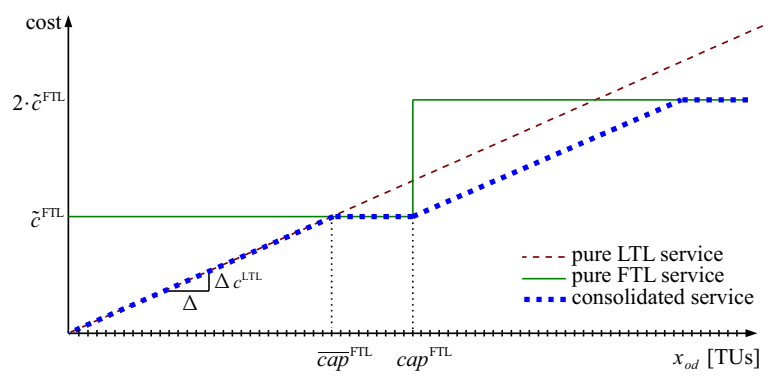

(DB Netz AG 2009). With this value and assuming a fully utilized train, the cost function (2) results in a corresponding function $c_{\mathrm{TU}}^{\text {rail }}(d)$ which measures the average cost per TU-km over a train travel distance $d$ by

$$
\begin{aligned}
c_{\mathrm{TU}}^{\text {rail }}(d) & =\frac{1}{38} \cdot € 0.58 \cdot 1560^{0.74} \cdot d^{-0.26} \\
& =\quad € 3.52 \cdot d^{-0.26}
\end{aligned}
$$

per TU-km. As expected, $c_{\mathrm{TU}}^{\text {rail }}(d)$ is clearly below $c^{\text {road }}(d)$, see Fig. 3 .

To derive transport cost rates applicable in the ITP model formulation, we transform (2) and (3) into rates for FTL and LTL transportation. The cost per train in FTL transportation is calculated from (2) by $\tilde{c}^{\mathrm{FTL}}=c^{\text {rail }}(d, 1560)$, where $d$ is set to the average travel distance between the terminals in the origin area and the terminals in the destination area of an ITP instance. The cost per TU in FTL rail transportation is calculated from (3) by $c^{\mathrm{FTL}}=c_{\mathrm{TU}}^{\text {rail }}(d)$. Finally, the cost per TU in LTL transportation is calculated by $c^{\mathrm{LTL}}=\varepsilon \cdot c^{\mathrm{FTL}}$, where $\varepsilon \geq 1$ reflects the surcharge that has to be met by the shipper when rail transport capacity is booked on a per-TU basis.

Having determined the service cost for D2D, LTL, FTL, pre-carriage, and post-carriage, the total cost for serving a customer exclusively from one production site and with one transport service is composed as shown in Tab. 2.

When selecting services for rail transportation, a further effect has to be taken into consideration. Since cost per TU are lower in FTL service than in LTL service $\left(c^{\mathrm{FTL}}<c^{\mathrm{LTL}}\right)$, selecting FTL services can be economically useful even if the block train capacity is not fully exploited by the shipped volume. The break-even load $\overline{c a p}{ }^{\mathrm{FTL}}$, at which chartering a block train at cost rate $\tilde{c}^{\mathrm{FTL}}$ is less ex-
Table 2: Transportation cost for relation $(s, c)$ under exclusive service selection

\begin{tabular}{cccc}
\hline & \multicolumn{4}{c}{ cost } \\
\cline { 2 - 4 } service & pre-carriage & main-carriage & post-carriage \\
\hline D2D & - & $n_{c} \cdot c^{\mathrm{D} 2 \mathrm{D}} \cdot d_{s c}$ & - \\
\hline LTL & $n_{c} \cdot c^{\mathrm{pre}} \cdot d_{s o}$ & $n_{c} \cdot c^{\mathrm{LTL}} \cdot d_{o d}$ & $n_{c} \cdot c^{\mathrm{post}} \cdot d_{d c}$ \\
\hline FTL & $n_{c} \cdot c^{\mathrm{pre}} \cdot d_{s o}$ & $\left\lceil\frac{n_{c}}{c a p^{\mathrm{FTL}}}\right\rceil \cdot \tilde{c}^{\mathrm{FTL}} \cdot d_{o d}$ & $n_{c} \cdot c^{\mathrm{post}} \cdot d_{d c}$ \\
\hline
\end{tabular}

pensive than shipping in LTL service on a per-TU basis, is computed by

(4) $\overline{c a p^{\mathrm{FTL}}}=\frac{c^{\mathrm{FTL}}}{c^{\mathrm{LTL}}} \cdot c a p^{\mathrm{FTL}}=\frac{\tilde{c}^{\mathrm{FTL}}}{c^{\mathrm{LTL}}}$.

It results as the ratio of cost per TU in FTL and LTL service multiplied by the load capacity of a full block train. Any shipment volume above $\overline{c a p}^{\text {FTL }}$ justifies chartering a block train to save cost over the LTL service. The resulting cost function for consolidated rail transports is shown in Fig. 4.

The consolidation of cargo that is shipped on a rail $\operatorname{arc}(o, d) \in \mathcal{B}$ is performed in three steps: First, the number of block trains $y_{\text {od }}$ to be chartered and fully used for FTL services is determined by

(5) $y_{o d}=\left\lfloor\frac{x_{o d}}{c a p^{\mathrm{FTL}}}\right\rfloor$,

where $x_{o d}$ denotes the number of TUs that the shipper projects to send via rail link $(o, d)$. Second, for the rest of the shipment, which is computed by $x_{o d}-y_{o d} \cdot c a p^{\mathrm{FTL}}$, FTL service is booked if it exceeds the break-even capacity, and LTL service otherwise. This decision is reflected by the binary variable $z_{o d}$ defined as

(6) $z_{o d}=\left\{\begin{array}{l}1, \text { if } x_{o d}-y_{o d} \cdot c a p^{\mathrm{FTL}}>\overline{c a p}^{\mathrm{FTL}} . \\ 0, \text { otherwise. }\end{array}\right.$

Having determined $y_{o d}$ and $z_{o d}$, the number of TUs send in LTL service is finally calculated by

(7) $x_{o d}^{\mathrm{LTL}}=\max \left\{0, x_{o d}-\left(y_{o d}+z_{o d}\right) \cdot c a p^{\mathrm{FTL}}\right\}$.

\subsection{Optimization model}

Next to the decision variables introduced for modeling the flow of TUs on rail arcs $\left(x_{o d}\right)$ and the freight consolidation for FTL and LTL services $\left(y_{o d}, z_{o d}, x_{o d}^{\mathrm{LTL}}\right)$, we also define variables $x_{i j}$ for the flow of TUs on road $\operatorname{arcs}(i, j) \in \mathcal{A}$. With these decision variables, the ITP is formulated as a mixed- 
integer programming (MIP) model as follows.

$$
\begin{aligned}
\text { [ITP] } \min \rightarrow Z & =\sum_{s \in \mathcal{S}} \sum_{c \in \mathcal{C}} x_{s c} \cdot d_{s c} \cdot c^{\mathrm{D} 2 \mathrm{D}} \\
& +\sum_{s \in \mathcal{S}} \sum_{o \in \mathcal{O}} x_{s o} \cdot d_{s o} \cdot c^{\mathrm{pre}} \\
& +\sum_{d \in \mathcal{D}} \sum_{c \in \mathcal{C}} x_{d c} \cdot d_{d c} \cdot c^{\mathrm{post}} \\
& +\sum_{o \in \mathcal{O}} \sum_{d \in \mathcal{D}}\left(y_{o d}+z_{o d}\right) \cdot d_{o d} \cdot \tilde{c}^{\mathrm{FTL}} \\
& +\sum_{o \in \mathcal{O}} \sum_{d \in \mathcal{D}} x_{o d}^{\mathrm{LTL}} \cdot d_{o d} \cdot c^{\mathrm{LTL}}
\end{aligned}
$$

subject to

$$
\begin{aligned}
& \text { (9) } \sum_{j \in \mathcal{O} \cup \mathcal{C}} x_{s j}=q_{s} \\
& \forall s \in \mathcal{S} \\
& \text { (11) } \sum_{o \in \mathcal{O}} x_{o d}=\sum_{c \in \mathcal{C}} x_{d c} \quad \forall d \in \mathcal{D} \\
& \text { (12) } \sum_{i \in \mathcal{S} \cup \mathcal{D}} x_{i c}=n_{c} \quad \forall c \in \mathcal{C} \\
& \text { (14) } \quad M \cdot z_{\text {od }} \geq x_{o d}-y_{o d} \cdot c a p^{\mathrm{FTL}}-\overline{c a p}^{\mathrm{FTL}} \\
& \forall(o, d) \in \mathcal{B} \\
& x_{o d}^{\mathrm{LTL}} \geq x_{o d}-\left(y_{o d}+z_{o d}\right) \cdot \operatorname{cap}^{\mathrm{FTL}} \\
& \forall(o, d) \in \mathcal{B} \\
& \text { (17) } \quad y_{\text {od }} \in \mathbb{N} \\
& \forall(i, j) \in \mathcal{A} \cup \mathcal{B},(o, d) \in \mathcal{B} \\
& z_{\text {od }} \in\{0,1\} \\
& \forall(o, d) \in \mathcal{B} \\
& \forall(o, d) \in \mathcal{B}
\end{aligned}
$$

The objective function (8) minimizes the total transportation cost. It comprises the cost of D2D, FTL, and LTL services together with the cost of pre- and post-carriages. Constraints (9) ensure that the total production volume of site $s$ is shipped to customers directly or to the intermodal terminals. Constraints (10) and (11) represent the inflow/outflow conditions for the terminals. Here, (10) ensures that all goods sent from production sites to a terminal in the origin area leave this terminal for terminals in the destination area. From (11), it is ensured that all goods arriving at a terminal in the destination area are shipped to customers. Constraints (12) ensure that customer demand is fulfilled. Constraints (13) to (15) affect the consolidation of cargo on rail links $(o, d) \in \mathcal{B}$ by setting decision variables $y_{o d}, z_{o d}$, and $x_{o d}^{\mathrm{LTL}}$. These constraints represent the MIP formulation of Equations (5) to (7) . In detail, Constraints (13) determine the number of used block trains that are fully loaded. Constraints (14) decide whether a further block train is chartered for the remaining TUs $\left(z_{o d}=1\right)$. Here, $M$ refers to a positive number equal or larger than $c a p^{\mathrm{FTL}}$. Finally, Constraints (15) determine the number of TUs for which LTL service is booked. The domains of the decision variables are defined in (16) to (18). Note that no integer condition is required for the flow variables in (16). These variables inevitably take integer values provided that production quantities, customer demands, and train capacity parameters are all integers.

It can be taken from model (8)-(18) that the ITP is a generalization of the classical transportation problem. Actually, it reduces to this problem if rail transportation is omitted by enforcing $x_{o d}^{\mathrm{LTL}}=y_{o d}=z_{o d}=0$. Nevertheless, the generalized problem remains a linear flow problem that is solvable by standard solvers even if the production sites, customers, and terminals compose an intermodal network with several hundred locations. Therefore, the MIP-solver ILOG Cplex 12.1 (ILOG 2012) can be used to solve ITP instances of practical size.

\section{Illustrative example}

An example is provided for gaining insight into the structure and diversity of ITP solutions. We investigate the selection of services and the transport flows that are found by the optimization model for a very simple network structure under various cost parameter constellations. The network is characterized by two production sites, three customers, exactly one intermodal terminal $o$ in the origin area, and one intermodal terminal $d$ in the destination area. Locations of the network nodes are chosen such that the rail distance between the intermodal terminals is $d_{o d}=1000 \mathrm{~km}$. The door-to-door road distances between production sites $s \in S$ and customers $c \in \mathcal{C}$, the pre-carriage distances between production sites and terminal $o$ as well as the post-carriage distances from terminal $d$ to the customers are shown in Tab. 3 (gray cells). Note that, for each combination of site $s \in \mathcal{S}$ and customer $c \in \mathcal{C}$, the total distance for 
an intermodal transport $\left(d_{s o}+d_{o d}+d_{d c}\right)$ is strictly larger than the corresponding direct door-to-door distance $d_{s c}$. This is because intermodal transports require a detour for visiting the intermodal terminals. Furthermore, road traffic networks are far more dense and, thus, usually approximate an airline distance closer than rail traffic networks can. Additionally, the customers' demands and production sites' outputs are given in the last row and last column of Tab. 3, respectively. The values have been chosen such that total production output equals total customer demand.

Table 3: Example parameters: Transport distances, demand \& production quantities

\begin{tabular}{rcccccc}
\hline & \multicolumn{3}{c}{ customer $c$} & term. & $q_{s}$ \\
& & 1 & 2 & 3 & $o$ & \\
\hline \multirow{2}{*}{ site $s$} & 1 & 1200 & 900 & 1100 & 150 & 150 \\
& 2 & 1100 & 1000 & 900 & 50 & 50 \\
\multirow{2}{*}{ term. } & $d$ & 300 & 150 & 50 & 1000 & - \\
\hline$n_{c}$ & & 110 & 70 & 20 & - & 200 \\
\hline
\end{tabular}

Table 4: Experimental setting: Cost ratio intervals

\begin{tabular}{lcc}
\hline & $\frac{c^{\mathrm{FTL}}}{c^{\mathrm{D} 2 \mathrm{D}}}$ & $\frac{c^{\text {dray }}}{c^{\mathrm{D} 2 \mathrm{D}}}$ \\
\hline lower bound & 0.1 & 0.1 \\
upper bound & 1.5 & 3.0 \\
step size & 0.0025 & 0.0025 \\
\hline
\end{tabular}

We first investigate the impact of changes of the cost rates on the selection of transport services. For this purpose, cost rates $c^{\mathrm{FTL}}, c^{\mathrm{LTL}}, c^{\text {pre }}$, and $c^{\text {post }}$ are varied within certain intervals. The D2D cost rate $c^{\mathrm{D} 2 \mathrm{D}}$ is determined as described in section 3.2. It is kept fixed and serves as a reference value when varying the other rates. To limit the number of possible parameter variations, we consider a fixed ratio between LTL transport cost and FTL transport cost per TU. We assume that LTL cost is $25 \%$ above FTL cost, i.e. we set $\varepsilon=1.25$ and derive $c^{\mathrm{LTL}}=1.25 \cdot c^{\mathrm{FTL}}$. We also assume that the preand post-carriage cost rates are equal and jointly refer to them as the drayage cost rate $c^{\text {dray }}=c^{\text {pre }}=$ $c^{\text {post }}$. In the experiment, the cost ratios $\frac{c^{\mathrm{FTL}}}{c^{\mathrm{D} 2 \mathrm{D}}}$ and $\frac{c^{\mathrm{dray}}}{\mathrm{c}^{\mathrm{D} 2 \mathrm{D}}}$ are considered. These ratios are systematically varied as specified in Tab. 4. From this full-factorial experimental design, we obtain more than 300000 parameter combinations. Model ITP is solved once for each combination using ILOG Cplex 12.1.

Figure 5 illustrates the percentage of the total transport volume that is shipped in intermodal rail/road transportation under each combination of cost ratios. This measure is also referred to as the intermodal share of transports. It can be seen that ten differently structured solutions turn out to be optimal with respect to specific constellations of the cost ratios. The intermodal shares of these ten solutions differ strongly. They range from a pure intermodal transport (solution 1), where all TUs are shipped on the rail link, to a pure D2D service (solution 10) where no customers are served by intermodal transport. The modal split of the ten solutions, i.e. the percentage of the total transport performance (measured in TU-km) carried out in the distinguished service modes, is shown in Fig. 6.

Further details about the ten solutions, including the number of chartered block trains $\left(y_{o d}+z_{o d}\right)$ and the number of TUs sent in LTL service $\left(x_{\text {od }}^{\mathrm{LTL}}\right)$ as well as in pre-carriage, post-carriage, and D2D relations are provided in Table 5 .

The cost ratios $\frac{c^{\mathrm{FTL}}}{c^{\mathrm{D} 2 \mathrm{D}}}=1$ and $\frac{c^{\mathrm{c} r a y}}{c^{\mathrm{D} 2 \mathrm{D}}}=1$ subdivide Fig. 5 into four quadrants. In the upper quadrants, $c^{\mathrm{FTL}}$ is larger than $c^{\mathrm{D} 2 \mathrm{D}}$ making D2D service the cost-efficient option for the very most constellations. Only if the drayage cost rate $c^{\text {dray }}$ is much lower than $c^{\mathrm{D} 2 \mathrm{D}}$, the saving in pre- and postcarriage can compensate the higher rail transport cost, leading to a few intermodal transports (solutions 4 and 6). However, in practice, FTL cost per kilometer is usually lower than long-haul D2D cost per kilometer. This means that the constellation shown in the upper quadrants is rather unrealistic. Similarly, short-distance drayage cost per kilometer is usually above long-haul D2D cost per kilometer. Hence, also the constellation of the two left quadrants is hardly met in practice. Realistic cost constellations, where $c^{\text {dray }} \geq c^{\mathrm{D} 2 \mathrm{D}} \geq c^{\mathrm{LTL}} \geq c^{\mathrm{FTL}}$ holds, fall into the lower-right quadrant of the figure. It is worth mentioning that all ten solutions are met in this quadrant. From this observation, it is found that already a very small instance of the ITP can show a variety of different solutions being optimal under specific transportation cost rates. Using Fig. 5, we further investigate the change of the solution structure following from the variation of one cost parameter under ceteris paribus conditions. Starting from solution 1, where all cus- 


\section{Figure 5: Intermodal share of transports under varied cost}

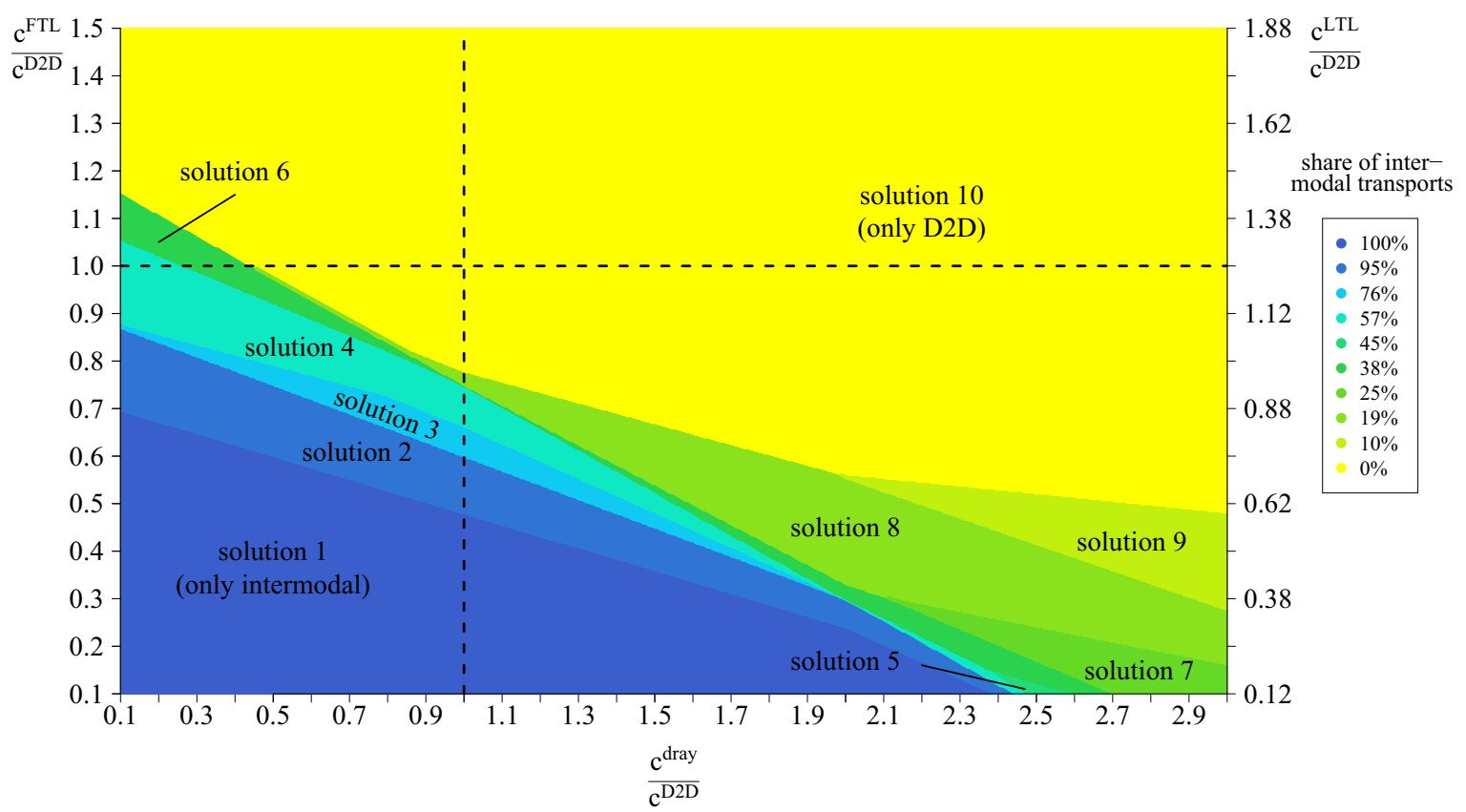

tomers are served by intermodal transport, the increase of $c^{\mathrm{FTL}}$ causes a gradual decrease in the intermodal share, see solution sequence 1-2-3-4-68-10. Interestingly, such change-overs often comprise shifting a number of TUs from one service to another, but not necessarily a shift of a complete customer demand between services. For example, as can be taken from column $x_{d 2}$ in Tab. 5 , the solution sequence 1-2-3-4 corresponds to a stepwise decrease in the fraction of demand of customer 2 that is served by rail. Gradual decreases in the intermodal share and the exchange of customer demands on the rail link are caused by the restricted production volumes of production sites and the consolidation effects in the intermodal transport. For these reasons, optimal solutions can bring out that customers are served by a combination of two or more services. We even observe two solutions ( 5 and 7 ) where the shipper makes use of all three services.

The analysis reveals the mechanism that determines whether LTL or D2D service is selected for a customer. A prerequisite for choosing LTL service is that $\frac{c^{\mathrm{LTL}}}{c^{\mathrm{D} 2 \mathrm{D}}}<1$ holds. This is because an LTL service causes additional detour cost for the preand post-carriages to and from the intermodal terminals. Hence, considering a customer $c$ that is projected to be served by site $s$, the shipper faces the question of whether the detour cost stays below the cost saving that results from rail haulage. In other words, the shipper needs to determine the maximum pre- and post-carriage distance up to which serving customer $c$ by site $s$ in LTL service is profitable. This question can be answered by assuming cost equality for the LTL and D2D transport cost functions in Tab. 2.

(19) $c^{\mathrm{D} 2 \mathrm{D}} \cdot d_{s c}=c^{\mathrm{pre}} \cdot d_{s o}+c^{\mathrm{LTL}} \cdot d_{o d}+c^{\mathrm{post}} \cdot d_{d c}$

If $c^{\text {dray }}=c^{\text {pre }}=c^{\text {post }}$ holds, Equation (19) can be reformulated as

(20) $d_{s c}=\frac{c^{\text {dray }}}{c^{\mathrm{D} 2 \mathrm{D}}} \cdot\left(d_{s o}+d_{d c}\right)+\frac{c^{\mathrm{LTL}}}{c^{\mathrm{D} 2 \mathrm{D}}} \cdot d_{o d}$.

Given certain cost rate ratios $\frac{\mathrm{c}^{\mathrm{dray}}}{c^{\mathrm{D} 2 \mathrm{D}}}$ and $\frac{\frac{\mathrm{L}}{\mathrm{LL}}^{\mathrm{T}}}{c^{\mathrm{D} 2 \mathrm{D}}}$ as well as the door-to-door distance $d_{s c}$ and the train haulage distance $d_{o d}$, the right-hand side of Equation (21) then delivers an upper bound for the drayage distance up to which LTL is economically preferable compared with D2D service.

(21) $d_{s o}+d_{d c}<\frac{c^{\mathrm{D} 2 \mathrm{D}}}{c^{\mathrm{dray}}} \cdot d_{s c}-\frac{c^{\mathrm{LTL}}}{c^{\mathrm{dray}}} \cdot d_{o d}$ 
Table 5: Detailed results for all solutions

\begin{tabular}{|c|c|c|c|c|c|c|c|c|c|c|c|c|c|c|c|}
\hline \multirow{2}{*}{ sol. } & \multicolumn{2}{|c|}{ intermodal share } & \multicolumn{2}{|c|}{ rail transport } & \multicolumn{2}{|c|}{ pre-carriage } & \multicolumn{3}{|c|}{ post-carriage } & \multicolumn{6}{|c|}{ door-to-door } \\
\hline & $\%$ & \# TU & $y_{o d}+z_{o d}$ & $x_{o d}^{\mathrm{LTL}}$ & $x_{1 o}$ & $x_{2 o}$ & $x_{d 1}$ & $x_{d 2}$ & $x_{d 3}$ & $x_{11}$ & $x_{12}$ & $x_{13}$ & $x_{21}$ & $x_{22}$ & $x_{23}$ \\
\hline 1 & 100 & 200 & 5 & 10 & 150 & 50 & 110 & 70 & 20 & O & O & O & O & O & O \\
\hline 2 & 95 & 190 & 5 & $\mathrm{O}$ & 140 & 50 & 110 & 60 & 20 & $\mathrm{O}$ & 10 & $\mathrm{O}$ & O & $\mathrm{O}$ & $\mathrm{O}$ \\
\hline 3 & 76 & 152 & 4 & O & 102 & 50 & 110 & 22 & 20 & O & 48 & O & O & O & O \\
\hline 4 & 57 & 114 & 3 & $\mathrm{O}$ & 80 & 34 & 110 & $\mathrm{O}$ & 4 & $\mathrm{O}$ & 70 & $\mathrm{O}$ & $\mathrm{O}$ & $\mathrm{O}$ & 16 \\
\hline 5 & 45 & 90 & 2 & 14 & 40 & 50 & O & 70 & 20 & 110 & O & O & O & O & O \\
\hline 6 & 38 & 76 & 2 & 0 & 26 & 50 & 0 & 56 & 20 & 110 & 14 & 0 & O & 0 & $\mathrm{O}$ \\
\hline 7 & 25 & 50 & 1 & 12 & O & 50 & O & 30 & 20 & 110 & 40 & $\mathrm{O}$ & O & O & $\mathrm{O}$ \\
\hline 8 & 19 & 38 & 1 & 0 & 0 & 38 & 0 & 18 & 20 & 98 & 52 & 0 & 12 & 0 & 0 \\
\hline 9 & 10 & 20 & 0 & 20 & 0 & 20 & 0 & O & 20 & 80 & 70 & 0 & 30 & 0 & 0 \\
\hline 10 & O & o & O & o & O & o & $\mathrm{O}$ & O & O & 80 & 70 & O & 30 & O & 20 \\
\hline
\end{tabular}

For example, with cost rates $c^{\text {dray }}=5, c^{\mathrm{D} 2 \mathrm{D}}=2$, $c^{\mathrm{LTL}}=1$, a given door-to-door distance $d_{s c}=$ $d_{23}=900 \mathrm{~km}$, and a given rail haulage distance $d_{o d}=1000 \mathrm{~km}$, the upper bound for the drayage distance is $160 \mathrm{~km}$. With the drayage distance $d_{2 o}+d_{d 3}=100 \mathrm{~km}$ for serving customer 3 from site 2, LTL service is less expensive than D2D service under the considered cost rates. The described parameter constellation leads to solution 9, where customer 3 is served in LTL service. If, however, the LTL rate increases to $c^{\mathrm{LTL}}=1.5$, the upper bound for the drayage distance changes to $60 \mathrm{~km}$. Now, the actual drayage distance of production site 2 and customer 3 exceeds the upper bound and, consequently, customer 3 is served by a door-todoor transport.

The conducted analysis allows to decide which service to choose (LTL or D2D) for a certain site-customer relation. Still, the complexity of the ITP, involving multiple sites, customers, terminals, and FTL consolidation hinders solving the entire problem through consideration of individual sitecustomer relations.

\section{Real-world case study}

In this section, we present a case study of a large commodity-producing company that resides in western Europe. In the next subsection we motivate the case study. Afterwards, we describe the production and distribution network that is used by the company. Finally, the cost drivers of the distribution system are subject of an analysis that is based on solving the ITP in different settings. The results are discussed and recommendations regarding the future development of the company's distribution system are drawn.

\subsection{Motivation}

We consider a company which is currently the market leader for a chemical product used in the construction industry. This good is produced at production sites located in Germany, Belgium, and the Netherlands. The sites produce the good for the entire European market. In the case study, we focus only on a part of the eastern European market, in particular Ukraine. Currently the company faces a strong growth of demand in this country. However, since places for production and consumption are far away from each other, a significant logistical effort arises to serve the customers. At the moment, the production and distribution is organized as follows. Customers order the goods on a monthly basis. From this data, the company generates a master production schedule specifying the monthly output of the production sites. Afterwards, each customer is informed which of the sites handles its order. Typically, goods are provided at the production sites and the customers organize truck transportation for each single TU. This policy for the distribution and payment of goods follows the incoterm 'Ex Works' (EXW), ICC (2010). It means that it is the customer's responsibility to organize and pay for the shipment of TUs from the providing site to their own front door. Next to the distribution cost, the customer also bears the risk involved in the transportation process. To get rid of the diverse risks involved in 


\section{Figure 6: Modal split as a percentage of total TU-km}
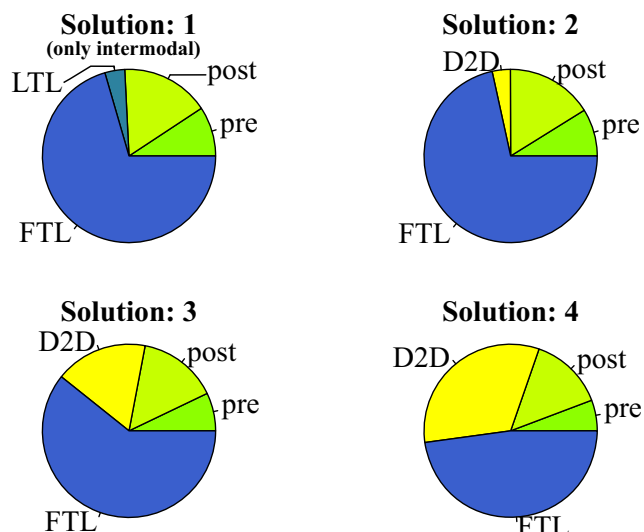

Solution: 5
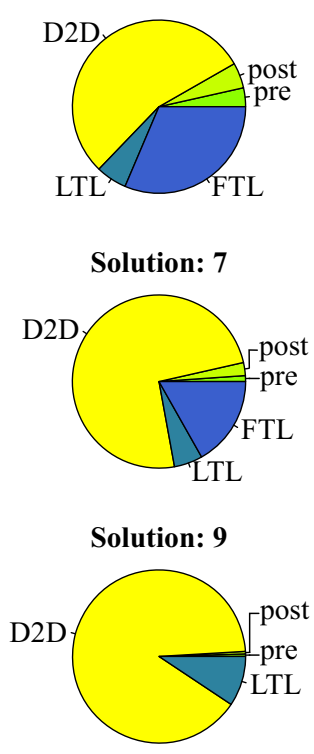

Solution: 4

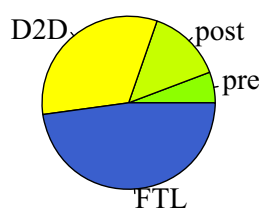

Solution: 6
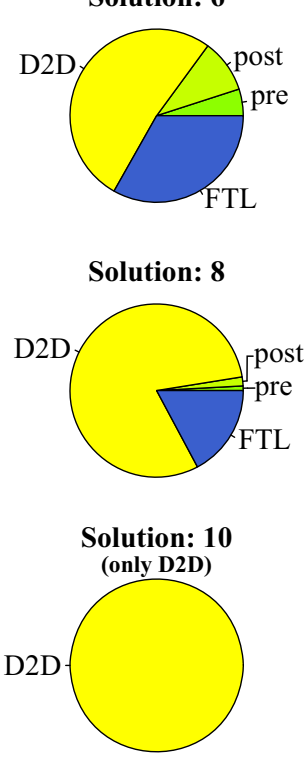

eastern Europe transportation, the company has favored the sketched trading conditions in the past. As a consequence of the behavior of the producer and the customers, the distribution of goods relies almost completely on D2D road transportation. On the other hand, the company faces increasing expectations of governmental authorities and NGOs regarding product responsibility and sustainable logistic processes. For these reasons, the company is thinking about insourcing the distribution process, by switching the EXW policy to the conditions of the 'Delivered at place' (DAP) incoterm. Here, the customer specifies the point of delivery in their home country, which is usually the customer's front door, and the producer has to pay

the cost and to bear the risk of the transportation. On the other hand, the company can control the flow of goods by selecting the used transportation services.

In the following study it is investigated whether intermodal transportation is a viable option for serving customers. Our analysis is based only on transportation cost rates where further costs like insurance and duties are beyond its scope. In a long-term perspective, the company is also interested in knowing the impact of changes in transportation cost on the optimal distribution policy. This is motivated by an expected increase of road transport cost (e.g., through emission fees, road tolls, and energy cost) and a possible decrease of rail transport cost (through infrastructural development of railway networks, subsidies for intermodal transport, and growing efficiency of rail transport providers). To investigate these questions, the distribution system of the company is modeled as an intermodal transportation problem and solved to optimality under various parameter constellations.

\subsection{Data}

The case study considers eleven production sites in western Europe and 35 customer locations in Ukraine. Some customers refer to a single company whereas others refer to local markets. The average distance of direct D2D transportation between sites and customers is $2213 \mathrm{~km}$. According to (1) this corresponds to the cost rate $c^{\mathrm{D} 2 \mathrm{D}}=0.64 €$ per TU-km.

We consider two different scenarios for the rail transport network, one scenario with only two intermodal terminals and the other scenario with five intermodal terminals. In the 2-terminal scenario, one terminal is located in the origin area and one is located in the destination area. The terminal in the origin area lies in central Germany. It is attractive for intermodal transportation as it is closely located to one of the production sites. Furthermore, the terminal lies in the eastern part of the origin area, which eases consolidation of cargo that is sent from other production sites eastwards to the customers in Ukraine. The terminal in the destination area is located near Kiev. This location constitutes more or less the center of the destination area. The rail link connecting both terminals has a length of $1765 \mathrm{~km}$. 
Table 6: Distances of rail links for 5-terminal scenario

\begin{tabular}{|c|c|c|c|}
\hline & & \multicolumn{2}{|c|}{ terminal $o$} \\
\hline & & 1 & 2 \\
\hline \multirow{3}{*}{ 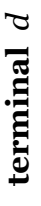 } & 1 & 1765 & 2360 \\
\hline & 2 & 1130 & 1800 \\
\hline & 3 & 2180 & 2850 \\
\hline
\end{tabular}

In the 5-terminal scenario, two terminals are located in the origin area and three terminals are located in the destination area. Next to the terminal in central Germany, a second terminal in the origin area is at Rotterdam. This facility is chosen because it is close to the westernmost production sites and it is capable of handling large volumes of chemical products. In Ukraine, two more terminals are selected in industrial centers, namely in Lviv and in Dnipropetrovsk. The terminals in the 5 -terminal scenario are connected by six rail links with distances shown in Tab. 6. The further terminals promise shorter drayage distances, which is expected to make intermodal transportation more attractive. We consider both scenarios to assess the benefit gained from a denser transportation network.

The average distances for pre-carriage and postcarriage are given with $462 \mathrm{~km}$ and $368 \mathrm{~km}$, respectively, in the 2-terminal scenario. In the 5 -terminal scenario, the average distance for pre-carriage to the nearest terminal is $313 \mathrm{~km}$ and for post-carriage it is $178 \mathrm{~km}$. Corresponding cost rates $c^{\text {pre }}$ and $c^{\text {post }}$ are computed as described in section 3.2. Thereby, the post-carriage rate is reduced by one third to represent the lower cost level in Ukraine. This reduction expresses the current difference in purchasing power between Ukraine and the European Union, see Worldbank (2012). In the 2-terminal scenario the cost rate for chartering a block train over the distance of $1765 \mathrm{~km}$ is calculated by $\tilde{c}^{\mathrm{FTL}}=$ $19.15 €$ per train-km. According to the regulations of western European railways, the block train capacity is limited to cap ${ }^{\mathrm{FTL}}=38 \mathrm{TUs}$, see DB Netz AG (2009) and Fiedler (2005). Although, regulations in eastern Europe are less strict, cross-border rail transport to eastern Europe is not allowed to exceed $c a p^{\text {FTL }}$, see Vogel (2000). Hence, we observe a corresponding cost in FTL transportation
Table 7: Cost rates used in the case study

\begin{tabular}{|c|c|c|}
\hline & 2-terminal & 5 -terminal \\
\hline$c^{\mathrm{D} 2 \mathrm{D}}$ & \multicolumn{2}{|c|}{$0.64 €$ per TU-km } \\
\hline$c^{\text {pre }}$ & $0.99 €$ per TU-km & $1.11 €$ per TU-km \\
\hline$c^{\text {post }}$ & $0.70 €$ per TU-km & $0.86 €$ per TU-km \\
\hline$\tilde{\boldsymbol{c}}^{\mathrm{FTL}}$ & $19.15 €$ per train-km & $18.50 €$ per train-km \\
\hline$c^{\mathrm{FTL}}$ & $0.50 €$ per TU-km & $0.49 €$ per TU-km \\
\hline$c^{\mathrm{LTL}}$ & $0.55 €$ per TU-km & $0.54 €$ per TU-km \\
\hline
\end{tabular}

of $c^{\mathrm{FTL}}=\frac{1}{38} \cdot \tilde{c}^{\mathrm{FTL}}=0.50 €$ per TU-km. From this we estimate the LTL cost rate $c^{\mathrm{LTL}}=0.55 €$ per TU-km, including a $10 \%$ surcharge $(\varepsilon=1.1)$. In the 5 -terminal scenario the cost rate for chartering a block train over an average distance of $2014 \mathrm{~km}$ is calculated by $\tilde{c}^{\mathrm{FTL}}=18.50 €$ per train-km with corresponding cost per TU-km of $c^{\mathrm{FTL}}=0.49 €$ and $c^{\mathrm{LTL}}=0.54 €$ in FTL and LTL transportation, respectively. All cost rates are summarized in Tab. 7. Furthermore, the case data consist of production quantities and customer demands for a one-month period as well as of traveling distances for road transports, see Tab. 9-11 in Appendix A.

\subsection{Results}

The company is interested in knowing the efficiency of the current way of distribution, which is based completely on direct D2D truck transportation. To answer this question, an ITP instance is created with the data reported above and rail transportation is suppressed by fixing the decision variables $x_{o d}^{\mathrm{LTL}}=y_{o d}=z_{o d}=0$. This way, a classical transportation problem is solved which leads to a transportation plan of total cost $€ 541900$ and a total transportation performance of 844214 TU$\mathrm{km}$. The solution is visualized in Fig. 7a where the width of a line reflects the intensity of the TU flow. This solution serves as a reference solution in the following study.

Solving the ITP instances for the 2-terminal scenario and the 5 -terminal scenario, we obtain the solutions shown in Figs. $7 \mathrm{~b}$ and $7 \mathrm{c}$, respectively. Here, the bold lines depict the flow of TUs along rail links. The dashed green lines refer to road transportation in pre- and post-carriage. In the solution of the 2-terminal scenario, $22 \%$ of TU$\mathrm{km}$ are performed in rail mode, leading to total cost of $€ 531568$, see Tab. 8. This represents a $2 \%$ saving realized by economies of scale in the 
Table 8: Case study results for different problem settings

\begin{tabular}{lcc}
\hline setting & $\begin{array}{c}\text { interm. } \\
\text { share }\end{array}$ & total cost \\
\hline ref. sol. (100\% D2D) & $0 \%$ & $€ 541900$ \\
\hline 2-terminal scen. & $22 \%$ & $€ 531568(-2 \%)$ \\
\hline 5-terminal scen. & $32 \%$ & $€ 516802(-5 \%)$ \\
\hline
\end{tabular}

rail transportation compared with the reference solution. In the 5 -terminal scenario, rail transport accounts for $32 \%$ of TU-km. This is explained by the shorter distances in the pre- and post-carriage and by the longer distances between rail terminals in the origin and destination area. The total cost of this solution is $€ 516802$, which is another $3 \%$ saving compared with the optimal solution of the 2-terminal scenario. In this scenario, customers located in the western Ukraine are still served by D2D service. For these customers, the drayage cost of intermodal transport would exceed the savings generated through the rail transport. It is also interesting to see that only two of the three terminals in the destination area are used in the optimal solution. Obviously, customers of western Ukraine can be served at relatively short D2D distances, while drayage distances exceed the upper bound (21). In consequence, the westernmost rail terminal of Ukraine cannot be used profitably for intermodal transportation at the assumed cost rates.

Although the cost savings of intermodal transportation are noteworthy in both scenarios, they alone do not justify to switch about $30 \%$ of TU volume from EXW to DAP terms because of the accompanying risk and administrative expense. However, since the company is facing an increasing public interest in climate protection, it considers changing the distribution system in order to reach a desired percentage of intermodal transport performance. In the following, we investigate how the optimal transport plan changes if a certain percentage of intermodal transports is enforced. For this end, restriction (22) is added to the ITP model which assures that at least $p \%$ of the total transport performance accounts for the rail mode.

(22) $\sum_{(o, d) \in \mathcal{B}} x_{o d} \cdot d_{o d} \geq p \cdot \sum_{(i, j) \in \mathcal{A} \cup \mathcal{B}} x_{i j} \cdot d_{i j}$

To assess the impact of this additional constraint, the ITP is solved for both scenarios under values of $p$ ranging from $0 \%$ to $65 \%$. Note that shares larger than $65 \%$ cannot be enforced in the considered scenarios because road transportation is not completely avoidable due to the drayage operations required in intermodal transportation.

The observed optimal distribution cost are shown in Fig. 8. It is found that the distribution cost is constant for $p<22 \%$ in the 2-terminal scenario. This is because $22 \%$ of intermodal transport performance is already realized when solving the problem without condition (22), see Tab. 8. Therefore, prescribing a minimum intermodal share below $22 \%$ has no economic effect on the optimal transport plan of the company. For $22 \% \leq p \leq 38 \%$, a cost increase is observed but total cost still stays below the cost of the reference solution. Within this range, additional intermodal transports are advantageous over serving all customers in D2D mode. For $p>38 \%$ total cost exceeds the cost of the reference solution, i.e. the intermodal transport no longer provides an economic advantage for the company. A similar observation is made for the 5 -terminal scenario, where total costs are constant up to $p=32 \%$. They are below the cost of the reference solution for $p<59 \%$. In other words, the 5 -terminal scenario shows a considerably larger potential for achieving a desired percentage of intermodal transports without exceeding cost of pure D2D distribution.

So far, we have analyzed the companies situation with respect to particular cost rates for FTL and LTL rail transportation. However, these rates are influenced by various factors like energy cost or subsidies for intermodal transportation. For this reason, we investigate in the following the sensitivity of solutions with respect to varying charter rates for block trains. We consider cost rates for trains between $\tilde{c}^{\mathrm{FTL}}=10.00 €$ and $25.00 €$ per train- $\mathrm{km}$ as reasonable. The cost rate is varied in steps of $0.1 €$ and corresponding cost rates $c^{\mathrm{FTL}}$ and $c^{\mathrm{LTL}}$ per TU-km are derived accordingly. The resulting shares of intermodal transport performance and total transportation cost are depicted in Fig. 9. The experiment shows that both, total cost and share of intermodal transport performance, depend strongly on the block train cost. The percentage of intermodal transportation exceeds $60 \%$ or even $70 \%$ for low train costs in the 2- and 5-terminal scenario, respectively. Especially for the 2-terminal scenario, demand for rail services is very elastic when cost ranges between 
Figure 7: Solutions for the case study

(a) Optimal network flow - reference solution (only D2D transports).

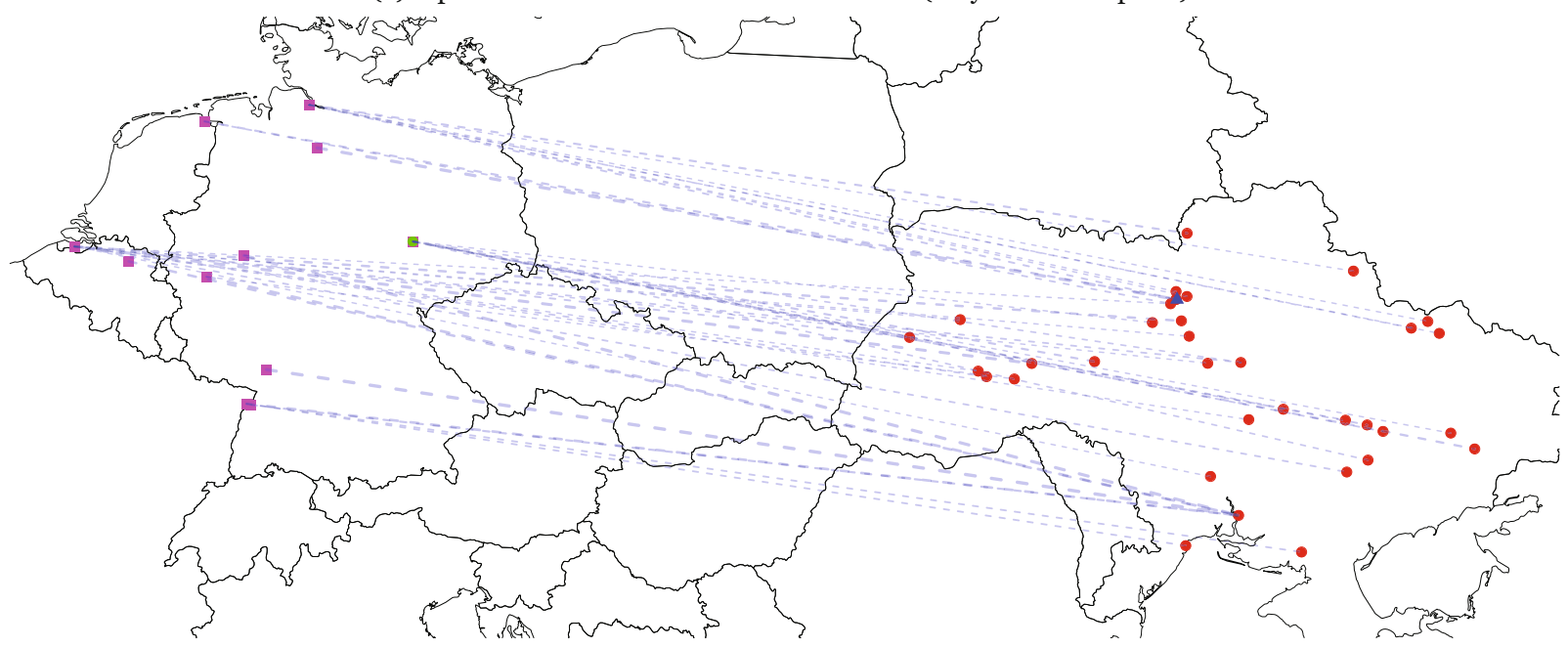

(b) Optimal network flow - 2-terminal scenario.

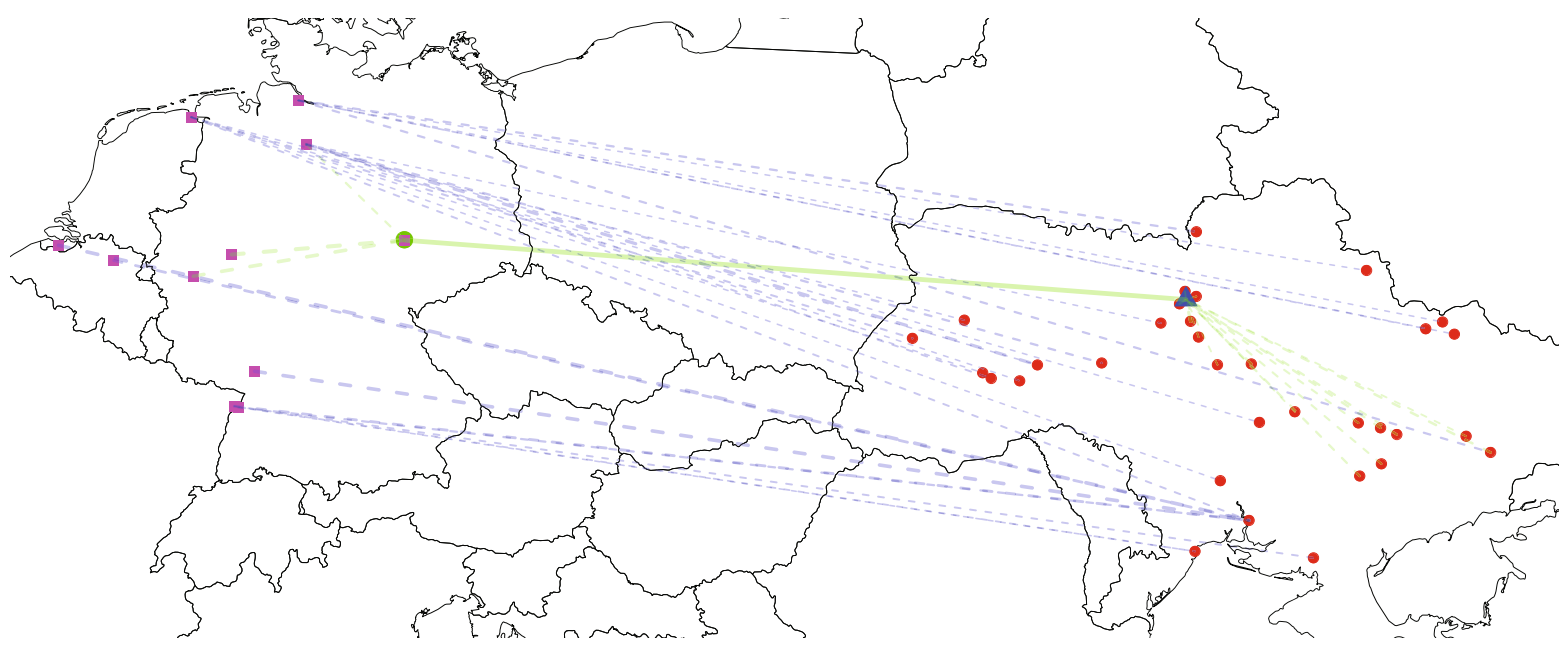

(c) Optimal network flow - 5 -terminal scenario.

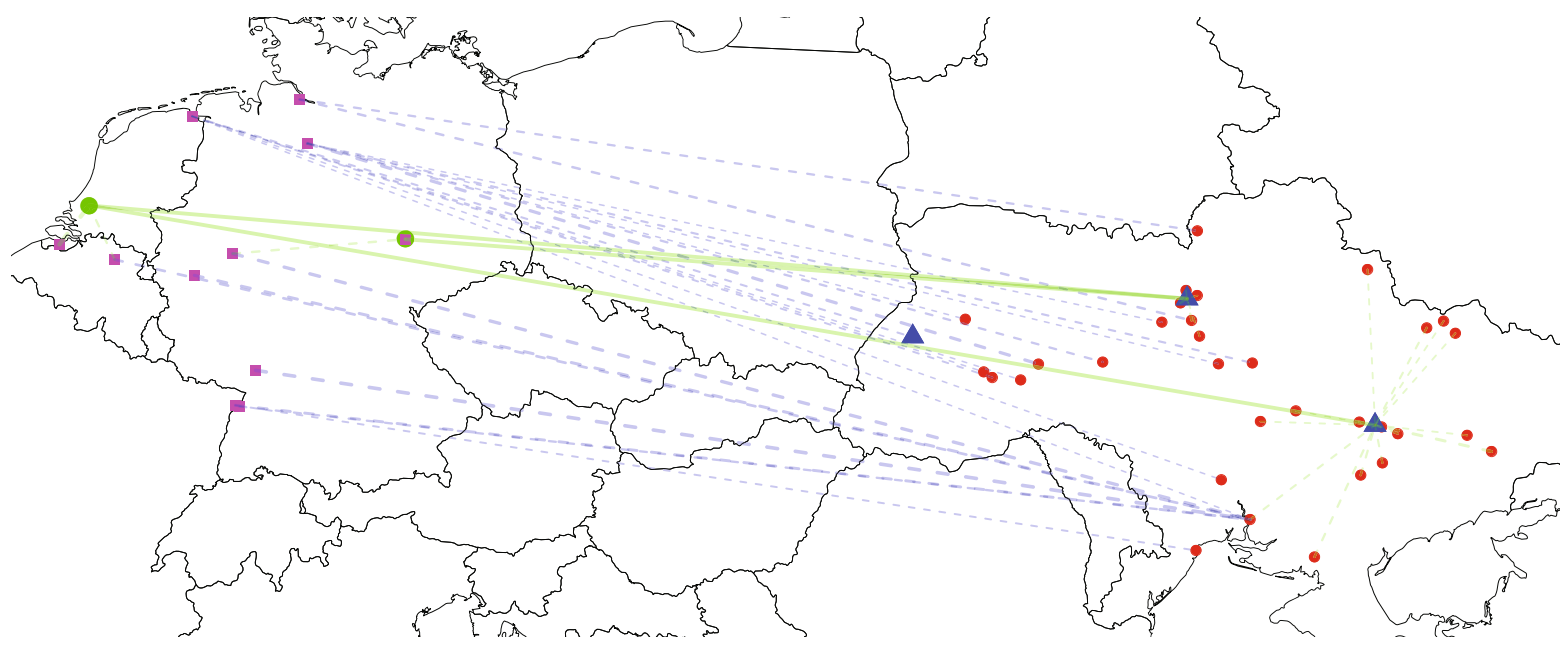


Figure 8: Total cost under varied values of $p$

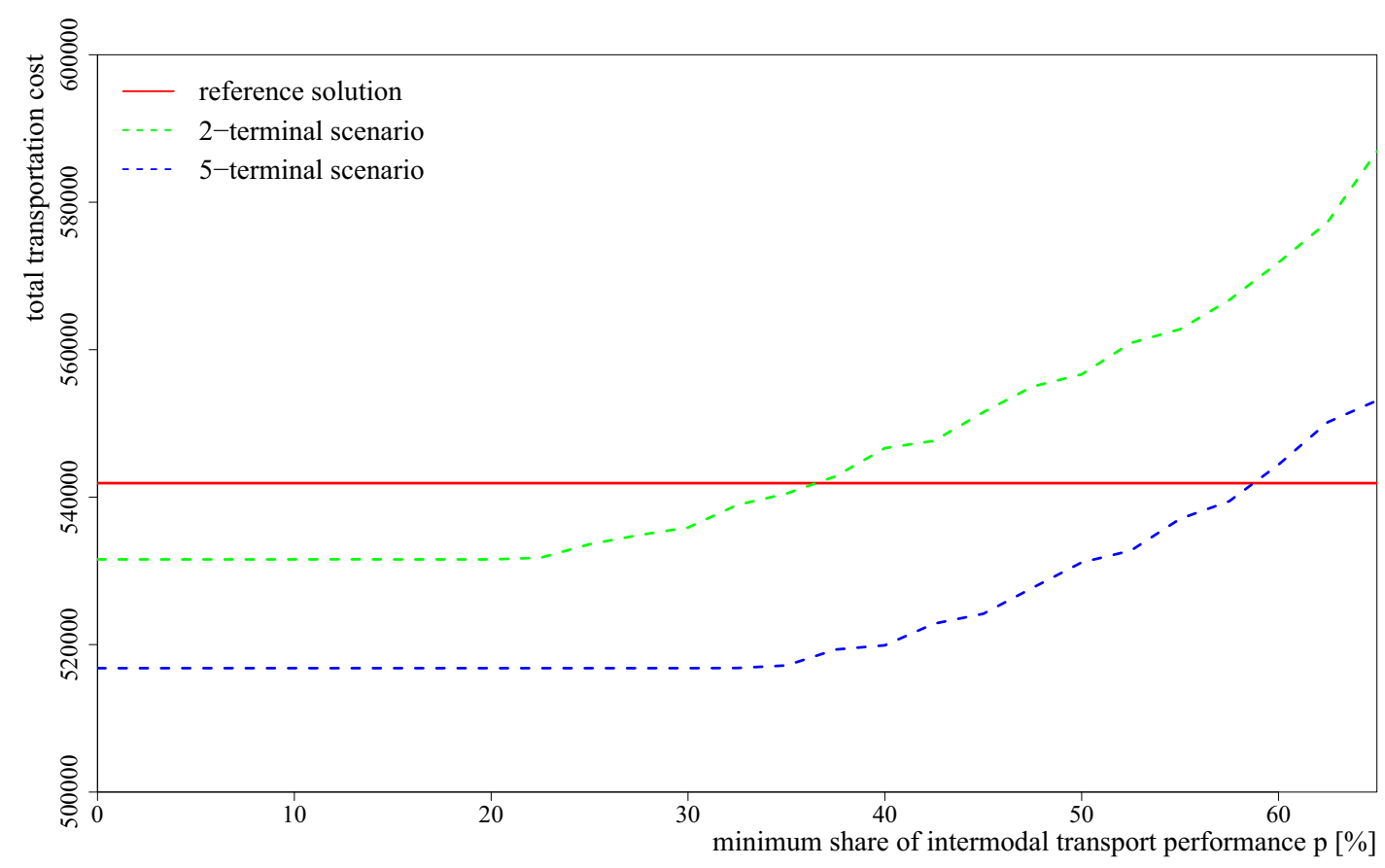

13 and $17 €$ per train-km. We take from Fig. 9 that observing the market for rail services carefully is a good recommendation for large shipper organizations. With their high transport volumes these companies have the power to negotiate lower rates and, thus, can generate a substantial saving of transportation cost that would justify switching incoterms.

Moreover, comparing the 2- and 5-terminal scenarios, it can be recognized that total transportation cost are always lower in the 5-terminal scenario, i.e. in the denser railway network. Of course, this effect diminishes the less rail transportation is involved in the distribution system as is caused by expensive train cost rates above $22 €$ per train-km. On the contrary, for cheap train cost rates below 17 $€$ per train-km, the difference in total cost of both scenarios is almost constant. This is striking, as it means that a dense network cannot take higher advantage from very cheap train cost compared with a sparse network.

Finally, we analyze the interplay of LTL and FTL services to consolidate the rail transportation between western Europe and Ukraine. Here, the aim is to verify whether LTL transportation is an attractive alternative for the considered company given that per-TU transportation cost is usually larger than FTL cost per TU-km. For this end, we consider three selected FTL train cost rates. For each of these rates, we derive two LTL cost rates, namely $c^{\mathrm{LTL}}=\varepsilon \cdot c^{\mathrm{FTL}}$ with $\varepsilon=1.0$ and $\varepsilon=1.1$, respectively. Note that with $\varepsilon=1.0$, no incentive is created for the shipper to consolidate full block train loads. The resulting six ITP instances have been solved for both terminal scenarios.

For the 2-terminal scenario, the transport performance (measured in TU-km) achieved in the optimal solutions is depicted in Fig. 10. It indicates that the modal split clearly favors rail transportation, the lower the train charter rate $\tilde{c}^{\mathrm{FTL}}$ is. At the same time, the total transport performance measured over all modes of transportation grows with a decline of the train charter rate. This is explained by the growing influence of detours that are caused by the drayage operations in the intermodal transport chain. It is also observed in this figure that the LTL service is used by the company only, if the per-TU cost of LTL is equal to the per-TU cost of FTL $(\varepsilon=1.0)$. LTL service is not used if its cost are higher than the cost of the FTL service $(\varepsilon=1.1)$. Two different ways are observed to circumvent LTL services. In the first way (observed under $\tilde{c}^{\mathrm{FTL}}=19.15$ and $\tilde{c}^{\mathrm{FTL}}=10.00$ ), LTL is eliminated by chartering an additional block train 
Figure 9: Sensitivity of intermodal share and total cost

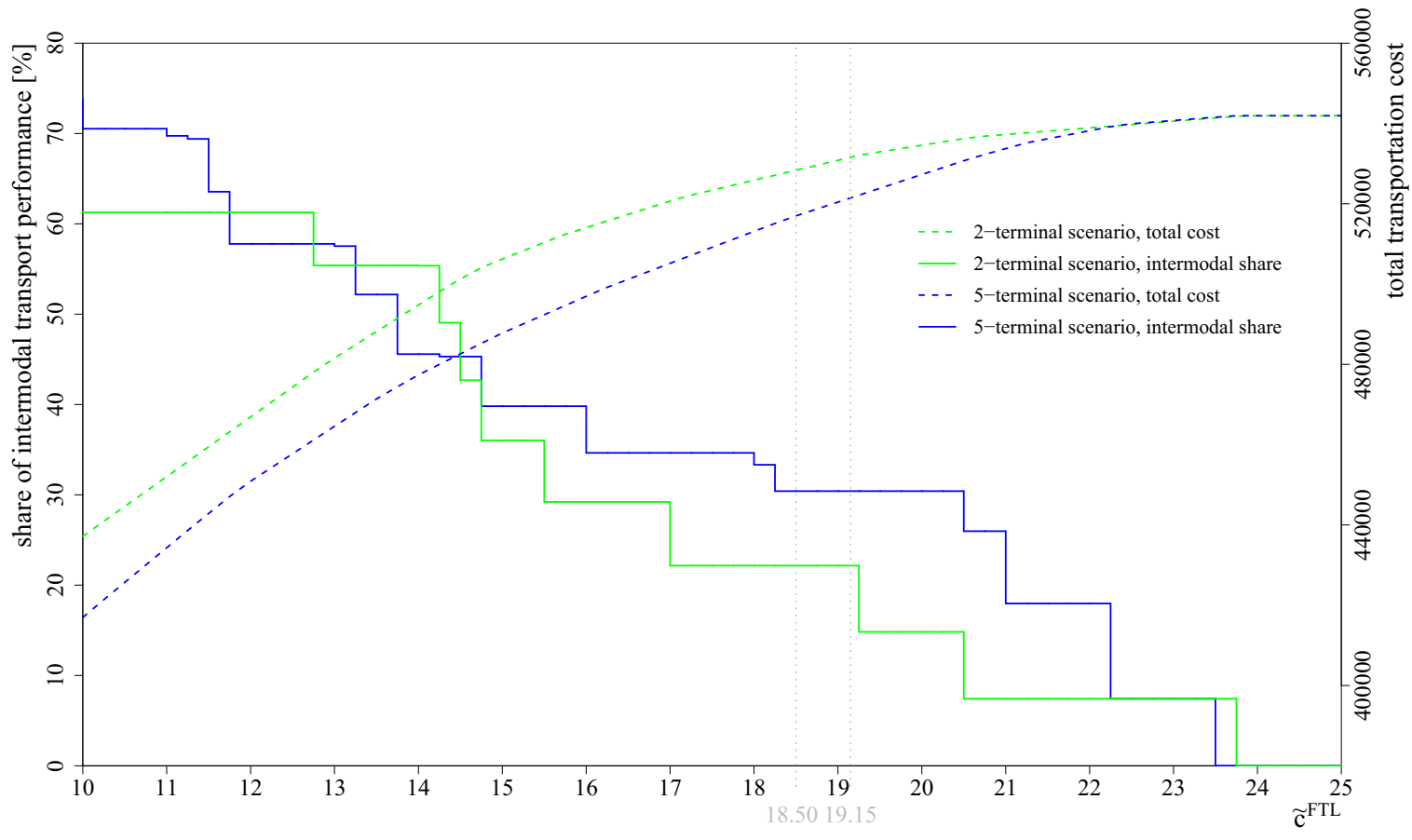

and filling it up with further TUs that are shifted from D2D service into FTL service. In other words, the shipper is given an economic incentive to consolidate cargo and intensify the use of intermodal transportation. In the other way (observed under $\left.\tilde{c}^{\mathrm{FTL}}=15.00\right)$, the shift of TUs happens from LTL service to road transportation. This option is chosen, if the LTL shipment is very small and, thus, cannot be filled up to block train load costefficiently.

The corresponding results of the 5 -terminal scenario are shown in Fig. 11. In this scenario, the original block train charter rate is $\tilde{c}^{\mathrm{FTL}}=18.5$ $€$ per train-km, see Tab. 7. In this network, LTL service is involved in the distribution also under a surcharge $(\varepsilon=1.1)$, at least for $\tilde{c}^{\mathrm{FTL}}=15$ and $\tilde{c}^{\mathrm{FTL}}=10$. This is because the transport volume shipped by rail is distributed among several terminals and rail links where some relations do not show enough volume for consolidating a complete block train. At the same time, drayage distances are shorter compared with the 2-terminal scenario which particularly favors LTL over D2D service even for small shipments.

To summarize the experiments, we draw the following findings. Under the assumed cost rates, a complete D2D service of customers is not the eco- nomically best option for the company. However, the cost saving that is possible by shifting shipments from road to rail is rather limited. On the other hand, enforcing high percentages of intermodal transportation, e.g., by legislative regulations, will increase distribution cost significantly. We also found that LTL service is not that important for shippers generating enough transport volume to consolidate rail carriage into full block trains. The density of the rail network has a considerable impact on the service selection of a company. A denser network enables shorter drayage distances which, in turn, causes that a higher percentage of rail transports is recommended not only from the environmental perspective but also from the economic perspective. Moreover, in such a network, the shipments split up into smaller volumes such that unconsolidated LTL shipments receive a certain relevance even for large shippers.

\section{Conclusion}

The paper generalizes the classical transportation problem to the intermodal transportation problem (ITP) by capturing decisions for selecting transport modes, transport services, and intermodal terminals. It is shown that this tactical planning problem 
Figure 10: 2-terminal scenario: Transport performance per service under varied cost

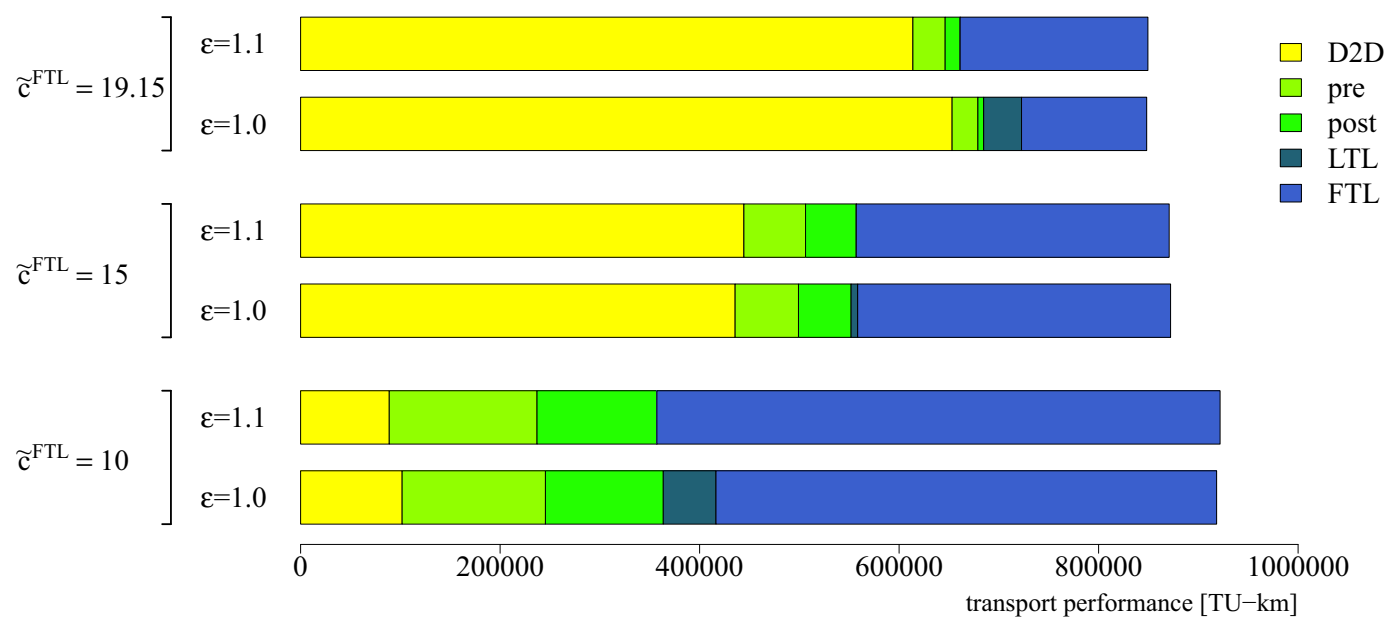

Figure 11: 5-terminal scenario: Transport performance per service under varied cost

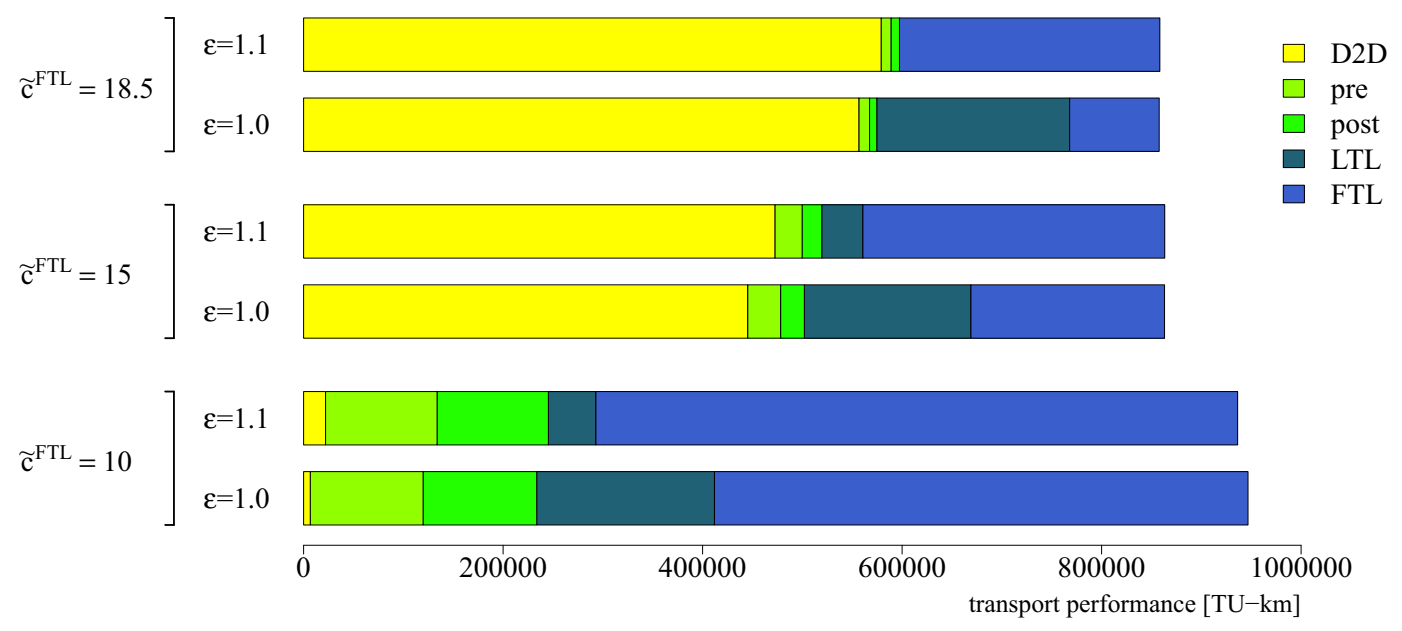

yields a variety of solutions being optimal under specific constellations of the transport cost rates. To determine the optimal modal split for a company's distribution system, an ITP instance can be solved with cost rates estimated close to reality. Furthermore, the impact of expected changes of transport cost can be assessed in order to adapt the distribution system of a company in future time. In the case study, we have verified that intermodal transportation is a profitable alternative to long-haul road transportation for the considered company. In contrast to smaller companies, this shipper can influence the tactical planning of an intermodal network because of its large transport volume. Smaller companies typically outsource the tactical planning to logistics service providers. Using our approach, companies can implement sustainable transport chains with a declining percentage of road transport and low transportation cost. The definition of the intermodal transportation problem comprises rail transportation from terminals in the origin area to terminals in the destination area. If a problem instance contains multiple terminals in one or both of these areas and if rail transportation is possible between terminals located within the same area, multi-stage consolidation as well as rail-based drayage operations come into the play. The development of models and solution methods for such problems is subject of future research. 


\section{Appendix}

Table 9: Case study parameters: Road transport distances, demand \& production quantities

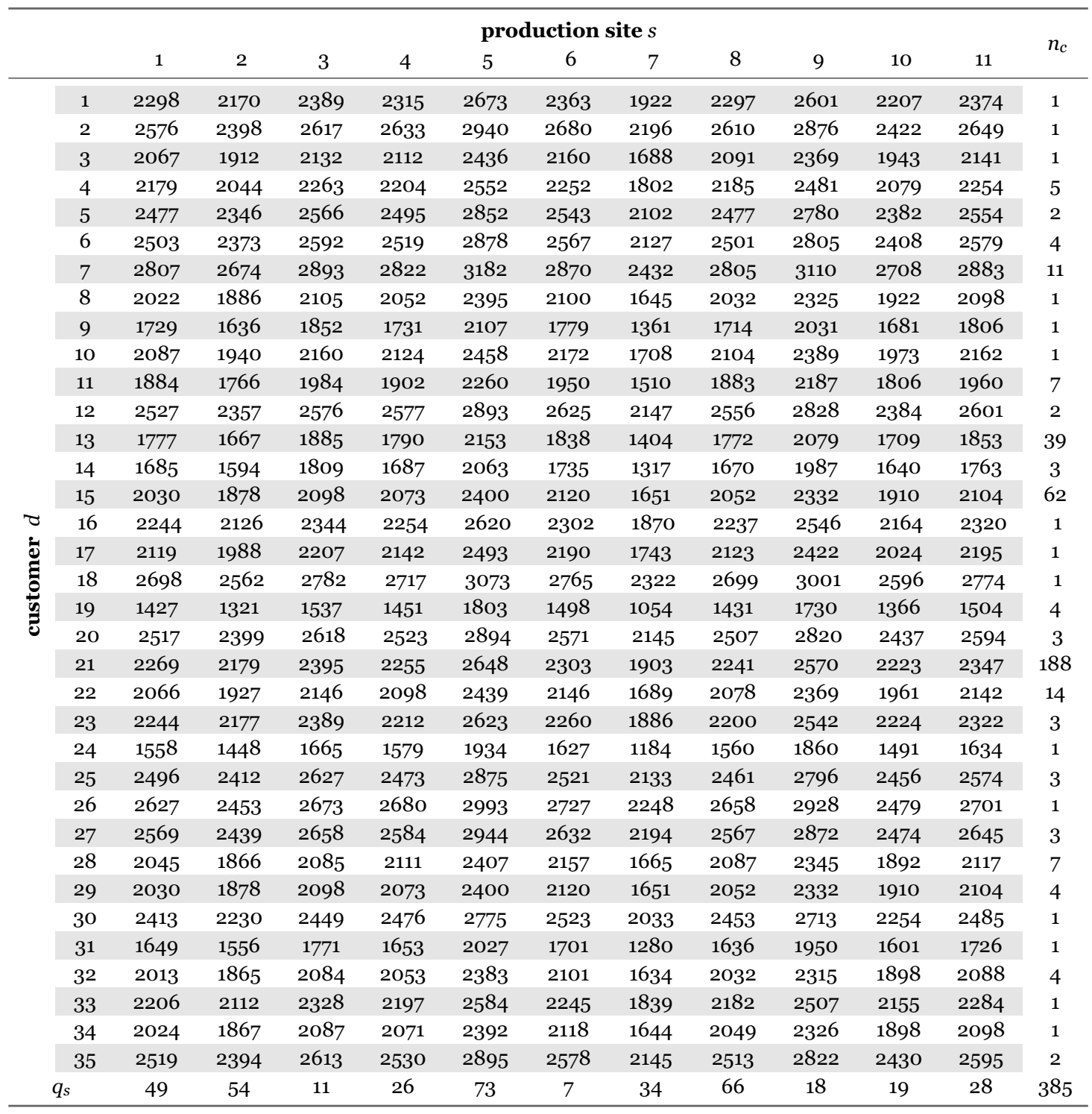


Table 10: Case study parameters: Road transport distances (pre-carriage)

\begin{tabular}{|c|c|c|c|}
\hline & \multicolumn{2}{|c|}{ terminal $o$} \\
\hline & & 1 & 2 \\
\hline \multirow{11}{*}{ 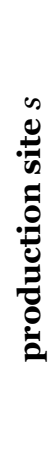 } & 1 & 379 & 326 \\
\hline & 2 & 349 & 479 \\
\hline & 3 & 525 & 296 \\
\hline & 4 & 507 & 558 \\
\hline & 5 & 750 & 109 \\
\hline & 6 & 545 & 566 \\
\hline & 7 & 1 & 679 \\
\hline & 8 & 473 & 523 \\
\hline & 9 & 680 & 135 \\
\hline & 10 & 421 & 500 \\
\hline & 11 & 453 & 277 \\
\hline
\end{tabular}

Table 11: Case study parameters: Road transport distances (post-carriage)

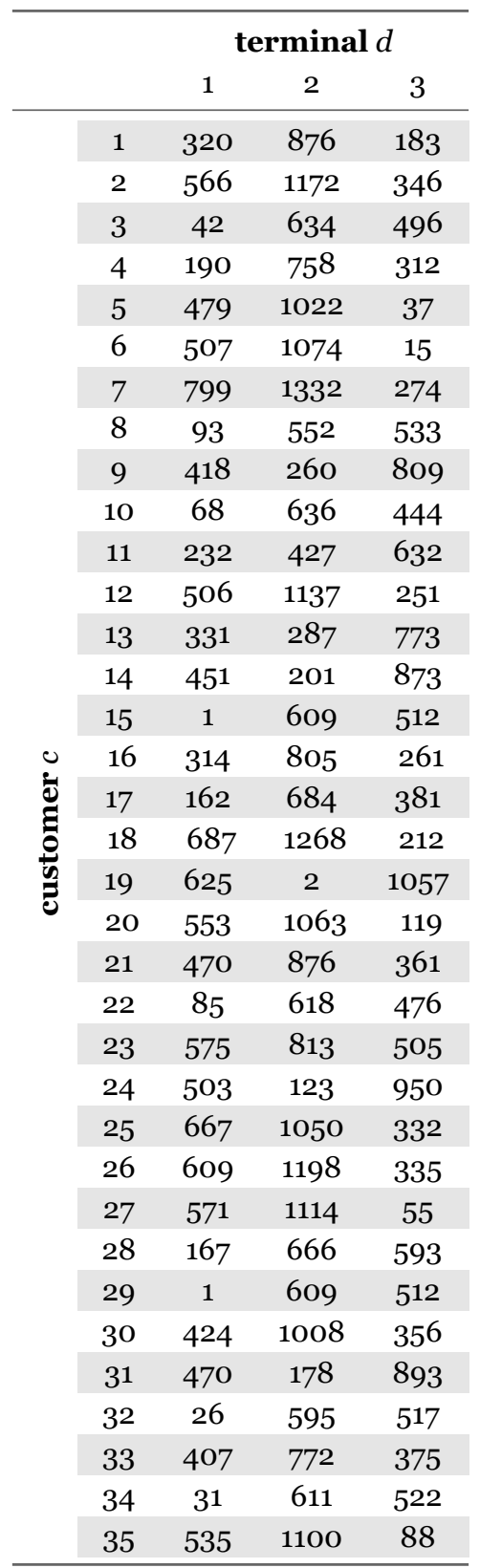




\section{References}

Arnold, Pierre, Dominique Peeters, and Isabelle Thomas (2004): Modelling a Rail/Road Intermodal Transportation System, Transportation Research Part E: Logistics and Transportation Review, 40 (3): 255-270.

Barnhart, Cynthia and Hugh D. Ratliff (1993): Modeling Intermodal Routing, Journal of Business Logistics, 14 (1): 205-223.

Boardman, Bonnie S., Eric M. Malstrom, Daniel P. Butler, and Michael H. Cole (1997): Computer Assisted Routing of Intermodal Shipments, Computers \& Industrial Engineering, 33 (1-2): 311- 314.

Caris, An, Cathy Macharis, and Gerrit K. Janssens (2008): Planning Problems in Intermodal Freight Transport: Accomplishments and Prospects, Transportation Planning and Technology, 31 (3): 277-302.

Chang, Tsung-Sheng (2008): Best Routes Selection in International Intermodal Networks, Computers \& Operations Research, 35 (9): 2877-2891.

Dantzig, George B. and Mukund N. Thapa (1997): Linear Programming 1: Introduction, Springer: New York, NY.

DB Netz AG (2009): Richtlinie 408, Modul 0711, http://fahrweg.dbnetze.com/file/2361562/data/rw_408_o109_final.pdf (Access date: 2012-08-29).

Erera, Alan, Juan Morales, and Martin Savelsbergh (2005): Global Intermodal Tank Container Management for the Chemical Industry, Transportation Research Part E: Logistics and Transportation Review, 41 (6): 551-566.

European Communities (2002): EU Intermodal Freight Transport: Key Statistical Data 1992 - 1999, http://www.uni-mannheim.de/edz/pdf/eurostat/o2/KS-AT02-O01-EN-N-EN.pdf (Access date: 2012-08-29).

Fiedler, Joachim (2005): Bahnwesen: Planung, Bau und Betrieb von Eisenbahnen, $S-, U$-, Stadt- und Strassenbahnen, $5^{\text {th }}$ ed., Werner: Düsseldorf.

Forkenbrock, David J. (2001): Comparison of External Costs of Rail and Truck Freight Transportation, Transportation Research Part A: Policy and Practice, 35 (4): 321-337.

ICC (2010): Incoterms 2010: ICC Rules for the Use of Domestic and International Trade Terms, http://www.iccwbo.org/products-and-services/tradefacilitation/incoterms-2010 (Access date: 2012-08-29).

ILOG (2012): IBM ILOG CPLEX Optimizer, http://www.ilog.com/products/cplex/ (Access date: 2011-12-16).

Ishfaq, Rafay (2012): LTL Logistics Networks with Differentiated Services, Computers \& Operations Research, 39 (11): 2867-2879.

Ishfaq, Rafay and Charles R. Sox (2010): Intermodal Logistics: The Interplay of Financial, Operational and Service Issues, Transportation Research Part E: Logistics and Transportation Review, 46 (6): 926-949.
Janic, Milan (2007): Modelling the Full Costs of an Intermodal and Road Freight Transport Network, Transportation Research Part D: Transport and Environment, 12 (1): 33-44.

Janic, Milan (2008): An Assessment of the Performance of the European Long Intermodal Freight Trains (LIFTS), Transportation Research Part A: Policy and Practice, 42 (10): 13261339.

Kim, Nam Seok and Bert Van Wee (2011): The Relative Importance of Factors That Influence the Break-Even Distance of Intermodal Freight Transport systems, Journal of Transport Geography, 19 (4): 859-875.

Macharis, Cathy and Yvonne M. Bontekoning (2004): Opportunities for OR in Intermodal Freight Transport Research: A Review, European Journal of Operational Research, 153 (2): 400- 416.

Meng, Qiang and Xinchang Wang (2011): Inter- modal Huband-Spoke Network Design: Incor- porating Multiple Stakeholders and Multi-Type Containers, Transportation Research Part B: Methodological, 45 (4): 724-742.

Min, Hokey (1991): International Intermodal Choices Via Chance-Constrained Goal Programming, Transportation Research Part A: General, 25 (6): 351-362.

Nozick, Linda K. and Edward K. Morlok (1997): A Model for Medium-Term Operations Planning in an Intermodal RailTruck Service, Transportation Research Part A: Policy and Practice, 31 (2): 91- 107.

Smart, Mike and Simon Game (2006): Two Case Studies on Road vs. Rail Freight Cost,http://www.pc.gov.au/__data/ assets/pdf_file/o007/48373/subo41attachmentb.pdf (Access date: 2011-12-06).

Sörensen, Kenneth, Christine Vanovermeire, and Sylvie Busschaert (2012): Efficient Metaheuristics to Solve the Intermodal Terminal Location Problem, Computers \& Operations Research, 39 (9): 2079-2090.

Spasovic, Lazar N. and Edward K. Morlok (1993): Using Marginal Costs to Evaluate Drayage Rates in Rail-Truck Intermodal Service, Transportation Research Record, 1383: 8-16.

Taylor, G. Don, Frank Broadstreet, Timothy S. Meinert, and John S. Usher (2002): An Analysis of Intermodal Ramp Selection Methods, Transportation Research Part E: Logistics and Transportation Review, 38 (2): 117-134.

Verma, Manish, Vedat Verter, and Nicolas Zufferey (2012): A Bi-Objective Model for Planning and Managing Rail-Truck Intermodal Transportation of Hazardous Materials, Transportation Research Part E: Logistics and Transportation Review, 48 (1): 132-149.

Vogel, Hanspeter (2000): Verlängerung von Güterzügen: Möglichkeiten und Grenzen, Rail International, 31 (4): 22-27.

Worldbank (2012): World development indicators \& global development finance, http://databank.worldbank.org/ddp/home. do?Step $=12 \& \mathrm{id}=4 \& \mathrm{CNO}=2$ (Access date: 2011-11- 23).

Ziliaskopoulos, Athanasios and Whitney Wardell (2000): An Intermodal Optimum Path Algorithm for Multimodal Networks with Dynamic Arc Travel Times and Switching Delays, European Journal of Operational Research, 125 (3): 486-502. 


\section{Biographies}

Christian Bierwirth is Professor of Production and Logistics at Martin-Luther-University, HalleWittenberg, Germany. He holds a Diploma Degree in Mathematics from the University of Heidelberg and a Ph.D. in Business Administration from the University of Bremen. His research focuses on developing heuristics for complex scheduling problems from the fields of production and logistics. His work has been published in international journals like the Journal of Scheduling, OR Spectrum, Evolutionary Computation, the European Journal of Operational Research, the International Journal of Production Economics, Transportation Science and others.

Thomas Kirschstein holds a Diploma Degree in Business Economics from Martin-LutherUniversity Halle-Wittenberg.
He is currently working as a research assistant at Martin-Luther-University. His research interests include integrated planning of logistical processes in complex production networks and geometrybased robust statistical methods.

Frank Meisel holds a Diploma Degree in Transportation Engineering from the Technical University of Dresden and a Ph.D. in Business Administration from Martin-Luther-University Halle-Wittenberg. $\mathrm{He}$ is currently working as a researcher and teaching assistant at Martin-Luther-University. His research interests include supply chain management, transportation planning, and container terminal operations planning. He has published in the Journal of Scheduling, OR Spectrum, the European Journal of Operational Research, Transportation Science and others. 